\title{
Essays by International Experts Working on the Immunization Program in China
}

\author{
Alan Schnur, Edward John Hoekstra, Enis Barış, \\ Jessie S. Wing, K. Lisa Cairns, Lisa Ann Lee, Paul Rota, \\ Yvan J. Hutin, Craig N. Shapiro, Stephen Hadler, \\ Yasuo Chiba, Hiroshi Yoshikura, Andrea Gay, \\ Lahouari Belgharbi, Mac W. Otten Jr., Yoshihiro Takashima, \\ and Lance Rodewald
}

\author{
A. Schnur \\ Expanded Program on Immunization, World Health Organization China Office, \\ Beijing, P.R. China \\ E. J. Hoekstra \\ World Health Organization, Beijing, P.R. China \\ E. Barış \\ Europe and Central Asia, Health, Nutrition and Population Global Practice, World Bank, \\ Washington, DC, USA
}

J. S. Wing

National Immunization Program, U.S. Centers for Disease Control and Prevention, Seconded to WHO China Country Office, Beijing, P.R. China

K. L. Cairns

World Health Organization China Office, Beijing, P.R. China

\section{A. Lee}

Expanded Program on Immunization, World Health Organization Representative Office in China, Beijing, P.R. China

P. Rota

Division of Viral Diseases, Centers for Disease Control and Prevention, Atlanta, GA, USA

Y. J. Hutin

World Health Organization China Office, Beijing, P.R. China

WHO Global Hepatitis Programme, Strategic Information, Geneva, Switzerland

C. N. Shapiro

U.S. Centers for Disease Control and Prevention (CDC), Atlanta, GA, USA

National Immunization Program, China CDC, Beijing, P.R. China

S. Hadler

World Health Organization China Office, Beijing, P.R. China

Bacterial Diseases Division, U.S. Centers for Disease Control and Prevention, Atlanta, GA, USA

(C) Springer Nature Singapore Pte Ltd. \& People's Medical Publishing House, 
Y. Chiba

MCH Programme, Sapporo, Japan

H. Yoshikura

National Institute of Infectious Diseases, Toyama, Japan

A. Gay

Children's Health Program, United Nations Foundation, Washington, DC, USA

L. Belgharbi

Country Regulatory Support (CRS), Regulatory Systems Strengthening (RSS) Team,

Regulation of Medicines and Other Health Technologies (RHT), Department of Essential Medicines and Health Products (EMP), World Health Organization, Geneva, Switzerland

Center of Excellence of Regulatory Sciences and Good Regulatory Practices, COFEPRIS, Minister of Health, Mexico City, Mexico

M. W. Otten Jr.

WHO China Country Office, Beijing, P.R. China

Y. Takashima

Expanded Program on Immunization, Western Pacific Regional Office, World Health

Organization, Manila, Philippines

L. Rodewald $(\square)$

Expanded Program on Immunization, World Health Organization China Office,

Beijing, P.R. China

e-mail: rodewaldl@chinacdc.cn

\title{
10.1 Experiences with China EPI Evaluations
}

\begin{abstract}
Alan Schnur
Evaluation has been an important component of the global Expanded Programme on Immunization since its inception in the 1970s. China emphasized evaluation from the very beginning of the national immunization program, with concurrent and retrospective evaluations given an integral role in the EPI and polio eradication efforts in China. At the start of the EPI program, three formal comprehensive evaluations were planned to identify successes and problems at each stage of the program and to make proposals for further improving activities. The first evaluation assessed achievement of the target of $85 \%$ immunization coverage at provincial level by 1988 , the second $85 \%$ coverage at county level by 1990 , and the third $85 \%$ coverage at township level by 1995 . These evaluations included international experts and were comprehensive reviews of the EPI, going beyond just considering coverage, to look at program quality aspects such as cold chain, safe injections, disease surveillance (to assess impact of the program on the target diseases), training, and sustainability. The evaluation methodology adopted required international teams to make visits to all levels, including township and village levels, to review the work, which provided international experts with an opportunity to review the work, and see life in China, at all levels.
\end{abstract}


I first met EPI workers from China in 1987, during a Comprehensive EPI Programme Review in Myanmar, where a team had been sent to take part as observers. I was impressed with the knowledge and interest of the observers from China and also that China was sending a team to learn how EPI reviews were conducted in other countries. I later found that besides the team attending the EPI review in Myanmar, which was organized with the support of WHO SEARO where I was EPI Technical Officer, China also sent teams to observe EPI reviews in countries in other WHO regions. This reflected the priority placed on evaluation and the systematic way that China's EPI program was preparing for its first national EPI evaluation. I was surprised that some of the observers from China at this review were quite knowledgeable about EPI and evaluation but could not speak English. All questions and discussions had to be done through an interpreter. In most developing countries, senior staff speak excellent English (or French in French-speaking countries), while only junior staff at local level do not speak fluent English and need an interpreter to translate. It became clear to me that while the Chinese observers did not speak much English, their knowledge and interest was excellent, and they were capable of discussing high-level and complex issues and problems.

My next interaction with EPI evaluation in China was after my reassignment to the EPI unit at the WHO Western Pacific Regional Office (WPRO) in Manila. I was one of the WHO international team members who participated in the March 1989 national comprehensive evaluation of the EPI target of $85 \%$ immunization coverage at provincial level, assigned to work with the teams in two provinces: Jiangsu and Shandong (Fig. 10.1).

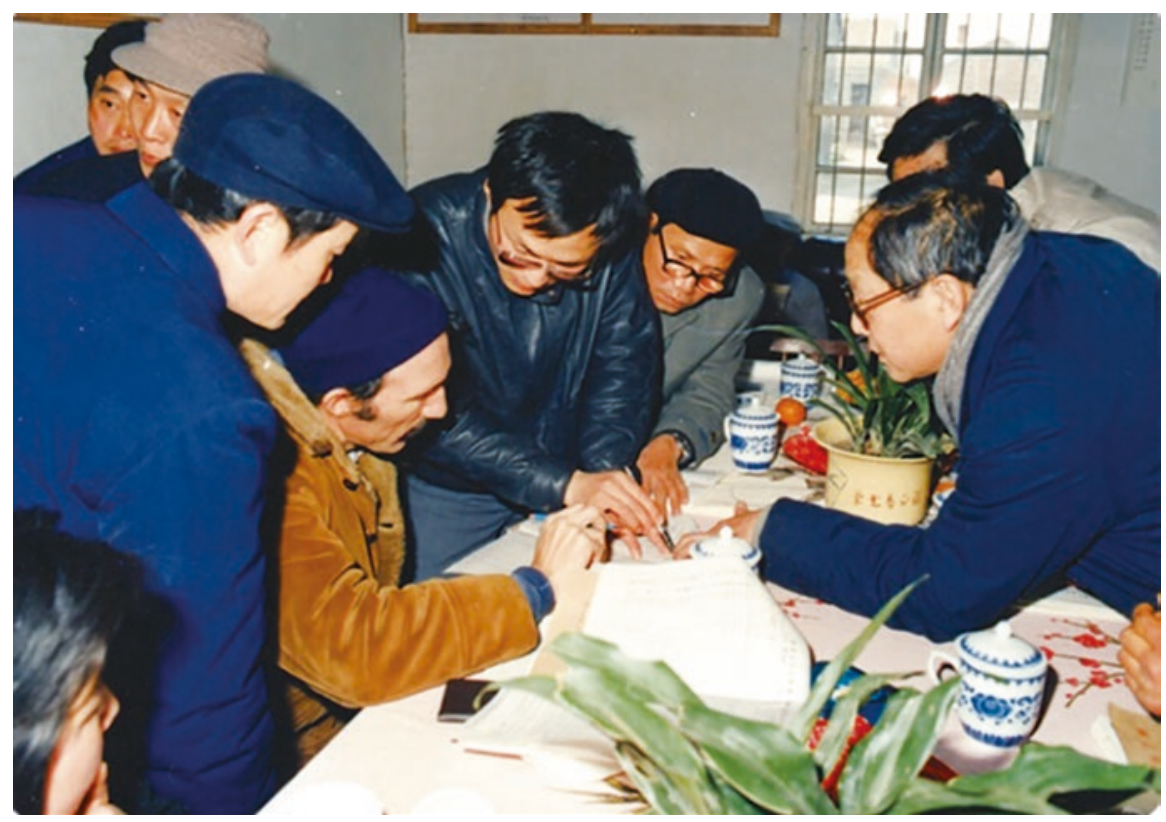

Fig. 10.1 Jiangsu EPI review record checking (March 1989) 
For the first visit to Jiangsu province, Dr. Yihao Zhang (a member of the Global Commission for the Certification of Smallpox Eradication and also China's National EPI Advisory Committee) was a member of our team. As it was the first time I was working in China, I was not sure how much one could push to revise the schedule after arrival and to randomly select places to visit, as required by the standard EPI review methodology. The briefing at WPRO in Manila had indicated that there was almost no room to select places to visit at random or to change the schedule prepared by the host province. However, to my surprise, during the opening briefing in Nanjing, when the provincial EPI team laid out the proposed program to visit Wuxi City (including a visit to the famous tourist attraction of "Taihu") and another very advanced county and prefecture, Dr. Zhang very calmly and politely responded that we would not be visiting these places. He informed the provincial EPI team that according to the review methodology, the review team needed to select the counties to visit according to the data. We then selected two prefectures and counties (with high and low coverage) and proceeded to visit them. I was very impressed with Prof Zhang's spirit of looking at the actual work and his knowledge about evaluation and the EPI program. I had helped organize, and participated in, many country comprehensive EPI reviews while working in SEARO, and during the field visits, I enjoyed the many chances to discuss with Dr. Zhang the EPI review methodology and utilization of the review questionnaires and forms. I felt that the review in Jiangsu met international standards, with the findings reflecting the actual situation. This was my first of many experiences with enthusiastic and hardworking evaluation team members in China.

Dr. Zhang returned to Beijing after the visit to Jiangsu and did not accompany the team to Shandong province. Unlike Jiangsu, Shandong provincial officials did not permit any changes to the pre-arranged schedule. We did have full access to the data and could find at the very end of the visit, while reviewing in depth the disease incidence rates and the breakdown of rates by prefecture, that there was an ongoing polio outbreak in one prefecture that had not been highlighted in the briefing. At the time, I thought that if Prof Zhang had been with us, we might have changed the prepared schedule and visited this prefecture since a disease outbreak indicates low EPI coverage or a cold chain breakdown. But we did have a chance to discuss on the last day the reasons for the high number of polio cases in this prefecture and to include this in our findings. Since the target was $85 \%$ immunization coverage at province level, Shandong was able to meet the target, even with low coverage in one prefecture. I learned that the work was overall of a very high standard but that there were still pockets of low performance and low coverage. I also relearned the lesson that having a respected and capable team leader, such as Dr. Zhang, can greatly affect the success of a mission and of a program.

However, while participating in many evaluations and assessments in China, I learned that not all staff were content to let the evaluators observe random program performance. During a polio assessment in one county, I visited two randomly selected townships and was impressed by the high quality of the work and the welcome banner prepared for the evaluation team at each place visited, even when the visit was made with very short notice. I commented on this to the county health 
officials, and they advised that they had requested all the townships to prepare carefully, since an evaluation team could visit any of them. I thought that while this could be seen as biasing the evaluation, by placing full emphasis on the county previously selected for the evaluation team's visit, it could also be viewed as "improving the work in all the townships in the selected county." On another occasion, during an assessment visit, I randomly selected the first house in a village to visit using the serial number of a currency note, where we found normal, basic conditions, and some problems with timely immunization. The township officials then offered to randomly select the second house, using the list of houses we had jointly prepared. The second house, while randomly selected, turned out to have a washing machine in the house and appeared quite well off compared to the first house, with the child immunized as per the schedule.

On another occasion, during a polio immunization day concurrent assessment in Yunnan province, I remember the evaluation team getting up early every day to travel to the selected places and working hard to visit as many immunization sites as possible to complete the assessment forms. One of the provincial team members was always enthusiastically getting everyone out to the transport in the morning, pushing everyone along with calls of "kuai-diar!," "kuai-diar!," or hurry up!

Following completion of assessment/evaluation missions, there were usually formal presentations of findings to senior $\mathrm{MoH}$ staff. I remember several of these presentation sessions in the traditional-style meeting room at the old $\mathrm{MoH}$ office near Houhai, attended by Vice Minister of MoH Dakui Yin. Vice Minister Yin, after carefully listening to the presentation of findings and recommendations by the international experts, would speak last to summarize the findings and what actions needed to be taken. He usually started off with some stories, and I could see some of the team members with less experience working in China puzzled about how the stories were related to the main issues presented. However, after starting his comments at the periphery of the main points, Vice Minister Yin would gradually move to issues closer to the center and by the end of his summation would succinctly address the key points and then explicitly talk about what would be done to address the recommendations. Those international experts who were familiar with his style simply waited for his comments to start edging closer to the center of the target until he reached "the bull's-eye." But all of the international experts left the presentation impressed that the main recommendations were understood and would be addressed.

Not only health workers were supportive of, and committed to, evaluation. On another occasion, during a polio immunization assessment in Qinghai province, a prefecture vice-governor accompanied the team during house-to-house visits to check whether children had received polio vaccine during the immunization day. We checked many houses and stayed out quite late, until it was almost dark. I requested that the vice-governor return, as we would take some time to carefully check all the required houses. She refused to return and stayed with us for the entire day, returning well after dark, energetically checking records and interviewing people in the villages about whether children had been immunized.

EPI evaluations provided international experts an opportunity to learn many things about the program, and about life in China, an interaction that I feel 
privileged to have had the opportunity to experience. During evaluations, there were always usually formal banquets for lunch and/or dinner, at each level. While reminiscing about the polio assessment in Qinghai, it brings to mind one banquet experience with which I would like to close this vignette. I visited Qinghai several times on assessment missions. On one of my last visits, provincial staff informed me that they had arranged a special lunch but didn't mention where it would be. Toasts ("ganbei") with alcoholic drinks are important parts of banquets in China and serve to establish rapport between the local workers and visitors (both national staff from higher levels and international experts). I must admit that I am not an enthusiastic alcohol drinker and did not greatly enjoy this aspect of the interaction during visits. During my time in China, there were many provinces in China known for heavy drinking at banquets, where large amounts of very strong alcoholic drinks would be consumed at the banquet table. Several provinces had a good claim to the "heaviest drinking province," but I believe that Qinghai would have been included among the top five heaviest drinking provinces by all international experts. On this particular occasion, Qinghai provincial staff had organized an excellent lunch in a well-known Moslem restaurant in Xining. Provincial staff informed me on entering the restaurant that it did not serve alcohol. I remember many, many outstanding and memorable banquets during my evaluation and assessment work in China, but there is a special place for the very friendly interaction during that alcohol-free lunch in Xining.

\subsection{The Foundation of Measles Case-Based Surveillance in China}

\section{Edward J. Hoekstra}

I arrived in China early 1998 as a World Health Organization (WHO) medical officer, assigned to continue supporting the polio eradication efforts underway in the country since the early 1990s. I had been to China on several previous occasions to support the polio eradication effort while working at CDC but would now be residing in Beijing for 2 years to concentrate on that support, as the ongoing polio campaigns were successful and moving forward toward the goal of eradication.

At the same time, it was evident that measles outbreaks throughout the country remained problematic with a measles incidence of $<10 / 100,000$ population during 1991-2000, even though China had a two-dose policy at 9 months and 7 years of age, and the reported cases of measles had been drastically declining since the introduction of measles vaccine in China in 1965 [1, 2]. It was becoming clear that measles control, including upgrading the surveillance, should be simultaneously addressed with my polio mission.

So as it turns out, I would now have two main goals to focus on for the coming 2 years that I resided in China, the eradication of polio and the further control of measles. The following is the story of how the program of measles control and elimination was established. 
On a cold spring day in early in 1998, Dr. Jingjin Yu, MoH; Dr. Zhiwei Yang, Chinese Academy of Preventive Medicine (CAPM); Dr. Steve Cochi, Centers for Disease Control and Prevention (CDC) Atlanta; and I, Dr. Edward Hoekstra from WHO, sat down in Beijing at the CAPM and discussed a collaboration between MoH, CAPM, CDC Atlanta, and WHO to start up a 3-year active case-based measles surveillance pilot project. The project was designed to establish the first step toward accelerated measles surveillance and control and included laboratory confirmation of cases, beginning in a limited area only, and building upon the systems used for polio eradication. While the polio infrastructure used laboratories at province level, the measles infrastructure needed laboratories at prefecture level because there would be too many cases to evaluate at the province level. It was intended that the operational experience obtained through this project would in the future be used nationwide.

In 1998, nationwide mass measles campaigns to eliminate measles were not politically feasible because polio eradication was ongoing, and the country had not yet been certified polio-free. Therefore, it was decided that the first step would be to develop case-based measles surveillance in the areas with a lower incidence of measles as it would be impossible to take blood samples from each case in areas with high incidence of measles. CDC Atlanta agreed to provide 500,000 USD annually for 3 years through WHO to support setting up province-wide surveillance in two provinces, and the Chinese government agreed to match the amount with 2 dollars for every dollar pledged.

While this pilot project was further designed, planned, and funded, the $\mathrm{MoH}$ with technical support form WHO and CDC Atlanta finalized and issued in 1998 the Plan for Accelerated Measles Control in China [3]. The plan grouped provinces into one of three control goals on the basis of average annual measles incidence. Provinces in group A had an average measles incidence of $<2 / 100,000$ population, and their goal was measles elimination. Provinces in group B had an average measles incidence of 2-15/100,000 population, and their goal was measles outbreak prevention (group B provinces are subdivided into groups B1 and B2, with measles incidences of 2 to $<5$ and 5-15 per 100,000 population, respectively). Provinces in group $C$ had an average measles incidence of $>15 / 100,000$ population, and their goal was measles control.

China had reported measles data to the National Notifiable Diseases Reporting System (NNDRS) since 1954. However, the reporting is passive, and the cases were only clinically confirmed. To increase the sensitivity and specificity of measles surveillance, the MoH issued guidelines in 1999 for the introduction of a measlesspecific surveillance system (MSS) [4]. Both the measles control plan and the national measles surveillance plan called for a phased approach, with different reporting requirements for provinces in different control groups. In Group A and B1 provinces, active surveillance for measles cases should be conducted every 10 days, and all suspected measles cases should be investigated, with blood samples obtained for serologic confirmation of acute measles infection. In group $\mathrm{B} 2$ and $\mathrm{C}$ provinces, the emphasis was on improving the timeliness of reporting and serologic confirmation of measles outbreaks. 
Also in 1999, the 3-year case-based surveillance pilot project was initiated in Shandong (group A) and Henan (group B1) provinces to gain experience with implementation of intensified measles surveillance, laboratories were set up at prefecture level in both provinces, equipment was installed, health and laboratory staff were trained, and guidelines for monitoring of active case-based measles surveillance were distributed.

After starting the pilot project in the first eight prefectures in Shandong in 1999, the CDC Shandong became aware of the number of measles cases and the increased workload related to case-based surveillance for health-care workers and laboratory staff. So by summer 1999, a province-wide measles campaign for children 8 months to 7 years of age was successfully conducted. As expected, this instantly further reduced the number of susceptible measles cases reported to MSS.

At WHO we knew from experience around the world that first conducting a mass measles campaign followed by introduction of a case-based surveillance was the preferred strategy to control measles. The pilot project in Shandong province with the overwhelming number of cases identified created the political will to conduct a mass campaign. This process also led to the desired measles control.

After 3 years, in 2001, the active case-based measles surveillance was reviewed positively [5] and became the foundation of the nationwide measles surveillance as we know it today.

\subsection{The World Bank (IDA)-Financed Disease Prevention Project}

\section{Enis Barış}

The World Bank (IDA)-financed disease prevention project, also commonly called as "Health-7," had as one of its two main objectives the prevention and control of vaccine-preventable diseases in the poorest ten provinces of China, including adding new vaccines to the Expanded Programme on Immunization. While I certainly enjoyed being the Bank's lead in the implementation of this project which allowed me to visit some of the poorest and remotest areas of mostly Western China, what I like most was its simplicity in design, yet its huge potential for making real impact in reducing mortality among the poorest children. Indeed the design was a tribute to Einstein who famously said "Everything should be made as simple as possible but not simpler," having the basic necessities for a successful EPA, with vaccines, cold chain, training, and supervision and management, but nothing else spurious, the implementation went as smoothly as one could imagine, corroborated by the Operations Evaluation Department's (OED) independent evaluation as project with a satisfactory outcome a rare rating for health projects in general.

This being said, I would like to emphasize three features of this project. First, this project came about at a time when there was a policy and leadership vacuum in health care and public health in China with a rather "laissez faire" attitude at the national level and serious financial and capacity constraints in poorer provinces. 
Many Chinese colleagues and their international partners were worried that the hard won past accomplishments despite extreme poverty in yesteryears are under serious threat by policies deferring financial responsibility for public health to provinces under the guise of encouraging financial autonomy and thus incentivizing them to introduce user fees for generating income even for essential services such as immunization. With this project, we were able to put a stop to it, at least in the 392 poverty countries in 10 poorest provinces.

Second, we were able to not only invest in cold chain and training but also were able to introduce some discipline in record keeping, and sound program management principles based on data and evidence, especially with regard to adverse event reporting, safe injection, and safeguarding the integrity of the cold chain for vaccine safety and efficacy. And this was done through one of the most exemplary partnership displays, at least in my record, the World Bank staff working hand in hand with WHO and US CDC colleagues, together with local, provincial, and national authorities in China at every field mission there was.

And finally, we were able to lay the groundwork for the introduction of hepatitis $\mathrm{B}$ vaccine, a first in China, and in my opinion, one of the greatest accomplishments of this highly successful project, at a time when about $10 \%$ of Chinese population were HBsAg positive. As a result, hepatitis B vaccine has been included in the EPI with the Ministry of Finance providing significant financing but also requiring provincial governments to bear the cost of purchasing vaccines while GAVI committing itself to finance the hepatitis B immunization in the interim, thus securing the sustainability of the EPI both in the medium and longer term.

These days, we do not talk much about immunization in China. This is so because there is not much to talk about, thanks to the incredible effort put by Chinese and international experts through our affectionately called Health 7 project.

\subsection{Polio Eradication in the Middle Kingdom: The Early Era of the Mid-1990s}

\section{Jessie S. Wing}

It was the 13th of December 1995... Beijing was a bright, sunny, dry, cold, dusty, and vibrant city of less than ten million official residents with a few cars but a sea of people weaving in and out in a synchronous wave of moving bicycles. Beijing was wonderful, amazing and thrilling. I was quite excited to start this new adventure as the second CDC Medical Officer assigned to China - the Middle Kingdom and the birthplace of my parents. There was so much history and so much work to do to eliminate polio that had exacted a heavy burden in China.

In the World Health Organization (WHO) Office in Beijing, there were only a few staff assigned at that time: Dr. Kingsley Gee (the WHO Country Director), Alan Schnur (WHO technical officer), and me as the medical officer from the Centers for Disease Control (CDC) for the Expanded Programme on Immunization (EPI). We had a few offices in a suite near the canal in the northeastern section of the city. 
Along with millions of other workers, I easily rode to work each morning on my Flying Pigeon bike from my WHO-assigned apartment in the Sanlitun area of Beijing where you could still hear the hawkers sonorously calling their wares from bikes and donkey-drawn carts. While I was in Beijing, I also provided clinical services at the US Embassy Clinic near the colorful Russian Market, Friendship Store, Chaowai, the outdoor Silk Market, and the Dirt Market where many transactions were made under China's burgeoning economy.

Some of our activities and accomplishments

- Acute flaccid paralysis (AFP) data: An important milestone was the ability to obtain AFP data from every county in China every month. Dr. Mac Otten's work to help "data-fy" China was fundamental. Mac, as the first CDC Medical Officer seconded to Beijing, Robb Linkins (CDC consultant), and Chinese Academy of Preventive Medicine (CAPM) helped to install and train provincial staff on CDC's free Epi-Info software and electronic surveillance. With the support of the Chinese Ministry of Health (MoH) and CAPM, AFP data were submitted from each county in China to their province then forwarded to Beijing each month. These data laid the foundation for my work to transform the county-level AFP data into meaningful maps for subsequent immunization activities, and the numerous epidemiology and laboratory reviews that followed.

- Surveillance, epidemiology, and mapping: I had "dualing" computers on my desk at the WHO office - one computer was for Epi-Info analysis and the other was a renegade Macintosh computer for mapping data. Each month, provinces/ cities would transmit their electronic AFP data to CAPM, where my CAPM counterpart would receive, clean, and compile the data into one file. CAPM would provide a cleaned data file, and I did the epidemiologic analyses and produced many maps to track the distribution of AFP cases in China each month.

- Any case suspected of having AFP was promptly investigated by local EPI staff, provincial officials, and national teams. Mopping up campaigns and Sub-National Immunization Days (SNIDs) were conducted, as needed. Several imported cases of wild polio virus reported in 1996 prompted a special visit to Yangon, Myanmar, by an international team. $\mathrm{MoH}$ also convened an international delegation for a rare visit to Tibet's Autonomous Region in 1997 to review their EPI data and processes for inclusion in China's polio certification application.

- Immunization activities: For polio vaccination, China used their domestically produced oral polio vaccine (OPV, a $1 / 4^{\prime \prime}$, ivory-colored, sweet dragee) that was crushed to administer to younger children. Diverse conditions throughout China necessitated special cold chain accommodations and various methods to target immunizations for the "floating population" (unregistered children). Some areas used horse-drawn carts and motor bikes to transfer OPV to remote areas to meet the ambitious goals of the NIDs. The level of cooperation, support, and effort throughout the provinces to vaccinate all NID-eligible children was remarkable. $\mathrm{MoH}$ led the NID efforts of the EPI staff along with CAPM, UNICEF, WHO, CDC, and Rotary, International. A record of 80 million children in China received OPV during the weeklong NIDs held during this time period. 
- International reviews: We hosted a series of international epidemiology, laboratory, and immunization reviews each year. Working closely with Director General Zhao Wang and Jingjin $\mathrm{Yu}$ at $\mathrm{MoH}$, specific provinces and counties were selected for site visits. We created special provincial profiles using the latest county-level AFP data, detailed epi/surveillance data files and maps, and laboratory data for the international consultants who came to China for the field visits, data reviews, and discussions. The status of laboratory specimens, laboratory processing, use of data (electronic and missing variables), analysis, and consolidation of wild virus specimens was discussed with Dr. Libi Zhang and other staff from CAPM, MoH, and the Western Pacific Regional Office (WPRO). This was the era that CDC consultants (Drs. Walt Dowdle, Steve Cochi, Olin Kew, Mark Pallansch) along with our WPRO colleagues from Manila (Drs. Rudy Tangermann and Ray Sanders) came to review China's local polio data in a series of special field visits.

- EPI training: In winter of 1997, we trained over 600 local EPI staff in Xinjiang, a large province in northwest China that was part of the venerated Silk Road. We also developed and hosted study tours to CDC/Atlanta for nearly 60 provincial EPI staff to receive advanced training in EPI, surveillance, and accelerated measles elimination methods.

- Public health infrastructure: Many of our field visits included provinces of north central and southwestern China, including Yunnan, Guizhou, Guangxi, and other areas with colorful but underserved minority populations. We calculated that I traveled in over half of this continental country, visiting EPI stations in many rural areas of China. At every level in China - village, township, county, prefecture, province, national level - we were well received and impressed with the commitment, hard work, and congeniality of the EPI and laboratory staff throughout the country. China's leaders and colleagues were sterling - including Director General Wang, Jingjin Yu (from MoH), Kean Wang, Libi Zhang, Xinglu Zhang, and Tao Xu (from CAPM) to name a few principal colleagues. We would not have been able to make progress in any of our polio work without their express support and dedication.

- Outcomes: Strong political support was illustrated by Jiang Zemin in posters distributed to many EPI stations in China and reminds us of the centralized, topdown infrastructure that facilitated the EPI work at that time. The collaboration among the partners (WHO, CDC, CAPM, MoH, UNICEF, Japanese International Cooperation Agency) illustrated the potential of a strong relationship and the outcome of the collective effort. With a strong mission and tenacity in the rank and file of resourceful and pragmatic staff at all levels in China, polio elimination (and eradication) progressed fairly quickly. After only 6 years, the widespread distribution of polio cases in China in 1990 decreased to only three cases of wild polio virus imported into southwestern China from Myanmar in 1996.

I think China demonstrated to the public health world that with an effective oral vaccine, reasonably good NIDs/SNIDs, good surveillance, electronic data, vigilance for clusters/outbreaks, development of a laboratory network, interventions as needed - in the context of an intact public health infrastructure - dedicated staff, 
and political will, the world's most populous nation eliminated polio in a relatively short amount of time. With these important components in place, this mega country could ultimately eradicate polio along with the other smaller countries in the region. The last polio case in the region was reported in Cambodia in 1997, and the Western Pacific Region (including China) was certified polio-free in 2000. In his 2015 Mountain Lecture at CDC/Atlanta, Bill Gates recalled that the BMGF (now a major global health partner) joined the polio eradication effort in India (another large country) in 1998.

Polio eradication was the initial reason that CDC staff were seconded to China, but subsequent CDC staff came to China for measles and other public health work as the WHO/Beijing office evolved. I believe the numerous epidemiology and laboratory activities and reviews that we carefully planned and implemented with $\mathrm{MoH}, \mathrm{CAPM}$, WHO, and CDC during this era helped develop a good model for subsequent EPI work. These important partnerships and relationships continue now in the transition to the use of inactivated polio vaccine in the Polio Eradication Endgame in China.

Every parent wants the best for their child, which was especially true for the numerous single-child families in China's 1.2 billion population. The Chinese characters, "prevention first," are particularly poignant for immunizations. While my parents left China because of world events, I think they would have been very pleased that I chose to live in Beijing and work to help the Middle Kingdom end the chapter on a devastating disease that was halted using a simple, two cent polio vaccine. With good infrastructure and an effective vaccine, China's progress was proof positive that polio eradication could be done at the macro and micro levels in a mega country with $1 / 6$ of the world's population - even in the early era of polio eradication of the 1990s.

\subsection{Answering Questions for a Nationwide Measles Supplementary Immunization Activity in China, 2010}

\section{K. Lisa Cairns}

In 2010, China conducted the largest measles supplementary immunization activity (SIA) which had ever been held in the world. At that time, I was serving as the team leader for the World Health Organization's (WHO's) Expanded Programme on Immunization team and as such had been actively involved in conceptualizing and then planning for this massive effort. The SIA aimed to vaccinate all children in targeted age groups regardless of previous vaccination history. Planning for the SIA had been an enormous undertaking - from ensuring adequate vaccine supply to enlisting the support of provincial health bureaus and preparing for adverse events following immunization. The SIA was accompanied by extensive social mobilization, which in turn generated many questions, particularly from the educated elite in China's large cities. The recommendation that all children be given a dose of measles vaccine, regardless of previous vaccine history, received particular scrutiny. 
WHO had coordinated the participation of a number of foreign observers eager to learn from China's ability to vaccinate so many children in such a short time. Several observers from the Pan American Health Organization, famous for spearheading measles elimination, were present. I listened in amazement as one of them mentioned to me that many people in the Americas had likely been vaccinated against measles five or six times as a result of nonselective SIAs and outbreak response activities. I could not help but think of the concern that we heard repeatedly expressed from Chinese parents that children who had already received two doses of measles vaccine might, as a result of the current SIA, receive three doses and marvel at differences in parental attitudes.

Dr. Peter Strebel, responsible for WHO's global measles program, also arrived to act as an observer. He and I were invited to participate in an open question-andanswer session for the public to be held in China's Centers for Disease Control and Prevention's (CCDC's) new communication center a day or two before the beginning of the SIA. We drove together through Beijing's car-jammed roads, moving slowly beyond the city to where fields opened up and traffic thinned, arriving eventually at CCDC's new, large, and ultramodern complex. We went through an enormous and impressive lobby into the state-of-the-art communication center. Individuals from CCDC were already there. Peter and I were directed to one side of the amphitheater where we waited patiently, albeit with the trace of anxiety which always accompanies such unscripted events. Shortly after, the questions began to arrive. The public e-mailed or phoned in queries which were translated for us into English. Peter and I would confer briefly, craft an answer, and have it translated to Chinese and sent out. As I sat surrounded by advanced electronics answering questions in real time from across the country, I thought of the remote villages in Sichuan that I had traveled to, and the contrasts of modern China seemed particularly striking. They were encapsulated for me in the two questions which I remember best: one seeking to verify that no imported vaccine would be used during the SIA, and the other, shortly after, asking why imported vaccine was not being used.

The SIA went on to vaccinate over 100 million children in China, demonstrating amazing planning and coordination. I visited many sites and gave a number of radio and television interviews. Nonetheless, my clearest memory of the SIA is sitting in the amphitheater, answering questions with Peter.

\subsection{Expanded Programme on Immunizations, WHO/China, January 1999 to May 2006}

\section{Lisa Ann Lee}

I spent 4 years as a Medical Officer and 2 years as Team Leader at WHO/China supporting the Expanded Programme on Immunizations. I had worked in many countries prior to my China posting and was very impressed and inspired by the dedication of counterparts at the Ministry of Health, China CDC and local health departments, and the Biological Product Institutes who worked tirelessly and over 
many years to build the EPI. The opportunity to contribute to China's development also had personal resonance as my parents emigrated from China as teenagers when the country was still impoverished and torn by war.

It was difficult choosing what to write about with so many good memories of working in China. When I arrived, Jingjin Yu was the Director of the EPI Division and Zhao Wang was the Director of the Department of Communicable Diseases. Both showed great leadership and skill in facilitating the effective collaboration between national and international experts on many priorities. Much of my first year in China was spent working at the China Academy of Preventive Medicine, later China CDC, on the China's documentation to present to the Regional Committee on Certification of Poliomyelitis Eradication. I spent a memorable week at the Rainbow Hotel working with national experts and EPI directors from all the provincial CDCs, many of whom I worked with in subsequent years. We all put a lot of effort into making the document of the highest quality since we knew it would be an important historical record of China's poliomyelitis eradication efforts, which began well before the start of the Global Poliomyelitis Eradication Initiative.

Two areas that I worked on which I felt had important impacts were advocacy for increased public funding for EPI and strengthening routine immunizations in Guizhou Province. When I arrived in 1999, much of the costs of vaccine delivery was financed by parents through out-of-pocket user fees, a result of market reforms which had extended to public health. While this worked in many areas, there was inadequate incentive to deliver vaccines to the poor, with vaccine-preventable disease burden higher in Western China and urban floating populations. An experience in one village where I found several unvaccinated young children made a strong impression. Their parents said they couldn't afford to pay the user fee and even though the village doctor had offered to vaccinate the children for free, they had refused because they felt that the village doctor was just as poor as they were. We started collecting more information on immunization financing in China and other countries in the region. In 2003, we had the opportunity to highlight financing constraints to delivery of public health services, with EPI as an example, in a high-level report "Public Health Options: Lessons Learned from SARS," submitted by WHO/China to the government as the epidemic ended. In the report, we also recommended that EPI be a benchmark program for monitoring the effect of recommended public health reforms. We were able to describe the health system and financing constraints faced by EPI in the 2004 EPI International Review Report, which included the results of a detailed immunization costing and financing field study supported by GAVI. In 2006, the State Council passed comprehensive new immunization laws making EPI vaccines and vaccinations completely free while at the same time greatly increasing central government funding for EPI. There is good evidence that inequities in access to recommended immunizations have greatly narrowed, and currently, the delivery of expanded preventive health services through the New Rural Cooperative Medical System is building on the foundation established by EPI.

The EPI in Guizhou province was also facing many challenges when we started a project there in 2003 to accelerate measles control and strengthen routine immunizations. At that time Guizhou had the highest measles incidence in China and accounted for the majority of measles deaths nationwide. Three-fourths of the 
counties had no budget for EPI, and over half of the village doctors received no government payment. Average per capita income was less than USD 200, and most of the province is mountainous and difficult to access. Despite these challenges, the project set ambitious goals of reducing measles deaths to near zero and measles incidence to very low levels through a measles catch-up campaign, increased government funding, increased accountability for EPI performance, and enforcement of existing school entry immunization laws that had yet to be fully implemented in any province.

When the project started, EPI staff seemed demoralized after years of being ranked at or near the bottom on most measures of EPI performance. Rankings are common and important in China, and provincial rankings are quite competitive. At the project inauguration meeting, we committed ourselves to moving Guizhou to the top of the national rankings and ensure that they stayed there. I felt there were initial doubts, but after the catch-up campaign in 2004, which benefited from careful support and planning by Yoshihiro Takashima, a Medical Officer on the EPI team, measles incidence in Guizhou fell dramatically and was even lower than Beijing's. This attracted a lot of positive attention and gave a huge boost to the program. The challenge was sustaining this achievement. In this we were very fortunate to have the strong support of Heng Bai, the Director of Disease Control at the Guizhou Health Bureau, who adroitly negotiated increased provincial funding for more immunization cards and vaccine supplies, the inclusion of EPI performance measures in the evaluation of political appointees, and the complex coordination between the Health and Education Bureaus needed to successfully implement school entry immunization requirements.

Alan Hinman, who was previously head of the Immunization Division at US CDC, was on the baseline project evaluation team and recommended "No shots, no school." It took almost 4 years to work out how to effectively operationalize those four words due to other laws mandating compulsory education. However, once operationalized, it turned out to be very effective given the high status of teachers in China. We conducted many training courses and supervision visits, and the project greatly benefited from continued involvement of Shuyan Zuo, a National Programme Officer on the EPI team. It's very encouraging to see that measles incidence in Guizhou province years after the project ended is still among the lowest nationwide.

\subsection{The Remarkable Progress of the Chinese Measles and Rubella Laboratory Network}

\section{Paul Rota}

The Measles Laboratory at US CDC was started in 1989 under the leadership of Dr. William Bellini. The laboratory was formed in response to a global resurgence of measles in the late 1980s. When I joined the Measles Laboratory in 1991, the laboratory already had a global reputation for being a leader in measles diagnostic methods and the genetic characterization of measles viruses. At that time, we were 
receiving many inquiries from international scientists who were interested in training at the US CDC. One of the first international trainees to visit us was Dr. Wenbo $\mathrm{Xu}$. Dr. Xu had been working in China's national polio laboratory and was asked to initiate laboratory activities for measles in China. Dr. Xu arrived in 1995 and quickly became a productive member of our laboratory. Within a few months, he had mastered most of the laboratory methods and was making great progress in characterizing measles viruses isolated from China. Dr. Xu was the first to describe genotype $\mathrm{H} 1$ which we now know has been the endemic genotype in China since at least 1993. In fact, we are continuing to monitor the circulation of genotype H1 viruses which is limited almost exclusively to China.

Before Dr. Xu returned to China in 1998, we sat together at my desk at US CDC and outlined a plan for a measles laboratory network in China. The plan called for reference laboratories in each of the 31 provinces with the basic serologic testing performed at the prefecture level. This network of laboratories would be supervised by the National Measles Laboratory at the China CDC in Beijing. At the time, I thought that this was a bold and very ambitious plan especially considering the limited resources available at the time.

My first trip to China was in 1999 as part of a review team for a CDC/WHO/ China CDC demonstration project. I was able to visit laboratories at all levels in China, and I remember that the prefecture laboratories were quite basic. There were a number of significant challenges including an inconsistent supply of commercial $\operatorname{IgM}$ test kits, ageing equipment, and substandard facilities. However, the demonstration project was successful in showing the case-based surveillance for measles with laboratory confirmation could be conducted in three, very populous Chinese provinces, Henan, Shandong, and Anhui.

Since 1998, I have traveled to China almost every year to either participate in the national laboratory training workshops or to conduct accreditation of the national and provincial laboratories. I have had the pleasure of visiting 12 provinces so far and have very fond memories of the outstanding hospitality of my Chinese colleagues. Over these visits, I witnessed a tremendous expansion and improvement of the Chinese National Laboratory Network. The SARS outbreak in 2003 hit China especially hard, but China made a major investment in laboratories following this outbreak resulting in substantial improvement in the capacity of the provincial laboratories. Under Dr. Xu's leadership, the China Measles and Rubella Laboratory Network made great use of these additional resources. Each province now has a modern, accredited laboratory; there are laboratories in 331 prefectures. Most of the provincial laboratories are capable of performing the full range of serologic and molecular tests, and many prefecture laboratories perform real-time RT-PCR in addition to testing for IgM. Through the efforts of the national laboratory, the provincial and prefectural laboratories have access to high-quality commercial kits for both IgM testing and real-time RT-PCR. The national laboratory provides annual training and proficiency testing for both serologic and molecular assays. The Chinese Measles and Rubella Laboratory Network was one of the first national networks to include testing for rubella virus in the standard laboratory protocols. The Chinese laboratory network now submits thousands of measles sequences and hundreds of rubella sequences to the WHO global sequence databases, MeaNS and RubeNS. 
China still has endemic measles, and the endemic genotype is H1. However, the Chinese Measles and Rubella Laboratory Network has been able to detect a handful of imported genotypes in a tremendous background of genotype H1. This is an amazing level of surveillance sensitivity in a country as large as China.

Of course, Dr. Xu could not accomplish all of this by himself, and one of his outstanding achievements has been mentoring the next generations of Chinese scientists. US CDC has had continual scientific exchange with China CDC. Over the years, many scientists have visited the US CDC in Atlanta to work on measles, rubella, and mumps, and we have published a large number of papers. Chinese scientists have also worked with the other Global Specialized Laboratories at Public Health England and the National Institute on Infectious Disease in Tokyo. In addition to supervising the extensive Chinese Measles and Rubella Laboratory Network, these now senior scientists are making contributions to the entire WHO Measles and Rubella Laboratory Network. They regularly attend WHO meetings and are serving in numerous advisory and supervisory capacities.

In summary, the progress of the Measles and Rubella Laboratory Network has been nothing short of remarkable. The network is fully capable to provide the highquality laboratory surveillance needed to document the elimination of measles in China in the near future. I am honored to have been part of this outstanding program, and I look forward to the day when genotype H1 is no longer detected anywhere in the world.

\subsection{Notable Experiences: The China-GAVI China Project and Hepatitis B Immunization}

\section{Yvan J. Hutin, Craig Shapiro, Stephen Hadler}

The China Ministry of Health-Global Alliance for Vaccines and Immunization Hepatitis B Project (China-GAVI Hepatitis B Project) was a multi-year project initiated in 2002 with the primary focus of increasing routine infant hepatitis B vaccination coverage in China. The project ultimately accomplished that objective and also improved hepatitis B vaccine birth dose timeliness and the general status of safe injections within the country. A unique aspect (compared with GAVIsupported activities in other countries) was that the project was overseen by a team that included an in-country international co-project manager in addition to a national co-project manager. This brief vignette contains observations from the three international co-project managers who served over the course of the project: (1) Craig Shapiro, who was involved in project conception and initial implementation (2001-2003); (2) Steve Hadler, who continued project implementation (20042007); and (3) Yvan Hutin, who continued project implementation with an emphasis on improving birth dose timeliness (2007-2011). All of us were inspired by the dedication and enthusiasm of the Chinese counterparts at all levels with whom we worked, and we feel privileged to have had the opportunity to be part of an activity that ultimately had such a broad impact in helping to change policy and improve public health. 
When Dr. Shapiro first arrived to Beijing in 1999 to work as a special consultant from the US Centers for Disease Control and Prevention (US CDC) to the China CDC (then referred to as the Chinese Academy of Preventive Medicine), the situation with respect to hepatitis B immunization was much different in China than it is today. It was before the SARS epidemic, which was a turning point in China in terms of investing dramatically in its public health system. It was also before the establishment of GAVI, which was a turning point in the world for prioritizing and investing in the introduction of new vaccines. Chinese leaders certainly recognized how important hepatitis B was as a public health problem in China (and given China's contribution to the worldwide burden of hepatitis B, global public health experts considered controlling hepatitis B in China as critical for global hepatitis B control). And Chinese health officials desired to provide hepatitis B vaccine to all infants. However, at that time in China, hepatitis B vaccine was available only if the vaccine was purchased by the family (often with a substantial markup), and an administrative fee was also charged - such markups and fees were an important source of revenue to cover the operating costs of clinics and the salaries of immunization providers. With such significant financial barriers to changing policy, the way forward, to make hepatitis B vaccine a routine immunization provided at no cost, was not entirely clear.

A variety of work activities and events came together in the early 2000s that enabled changes that ultimately led to hepatitis B vaccine being made a routine infant immunization in China. One was the completion of a World Bank immunization project, which had a component in which hepatitis B vaccine was provided to infants in several provinces at a lower price, through a subsidy. The World Bank study showed that even with the subsidy, hepatitis B vaccine coverage rates remained much lower than those of routinely provided vaccines such as DPT - vaccine price and user fees were significant barriers to receiving vaccine, especially among poor populations. Also around that time, a national immunization coverage survey showed wide disparities in hepatitis B vaccine coverage, with much lower coverage in poorer western provinces.

So with these lessons learned, and with the national desire at that time (and present to this day) to improve the general economic situation of the western provinces, conditions were primed for some type of change, and that is where GAVI played an important catalytic role. GAVI was in its initial stages and had the express purpose of promoting introduction of new vaccines, including hepatitis B, into countries around the world. However, while China in that era met the GAVI country eligibility criterion of per capita GDP less than USD 1000 (and certainly each of the western provinces - individually larger than many countries receiving GAVI support - met that criterion by wide margins), GAVI had not yet decided how to address China, India, and the Philippines, which had such large birth cohorts that providing support in the way that it was providing support elsewhere (essentially purchasing vaccine for a period of 5 years) would deplete GAVI's budget.

Several international teams visited China during 2001 and met with $\mathrm{MoH}$ official and country-based international staff at WHO, UNICEF, DFID, and the World Bank and the US Centers for Disease Control and Prevention to see if any type of 
collaborative activity could be put together that would help improve hepatitis B coverage. A pivotal moment was a meeting at the $\mathrm{MoH}$, at which GAVI representatives reviewed how hepatitis B vaccine was being provided in China, and remarked that such a mechanism (which involved generating profit) might be appropriate for "consumer products such as cars or refrigerators" but not for a public health intervention such as hepatitis B vaccination. Such a statement, recognized by all but never so clearly communicated to high-level MoH officials (with Ministry of Finance officials present), helped moved the agenda forward.

Over an ensuing series of visits and discussions, GAVI representatives worked with Chinese counterparts to devise the China-GAVI project as a subnational project focusing on providing support for western provinces and poverty-designated counties in the rest of the country and involving matching funding from China to purchase vaccine, syringes, and safety boxes. Hepatitis B vaccine would be provided free of charge to all infants in the target area and with a minor administrative fee that was to be phased out by the end of the project.

Several unique things were part of the project design:

The China-GAVI project was the first for which counterpart funding was provided by the recipient country to purchase vaccine. Because of this matching fund arrangement, an agreement, accompanied by a detailed project implementation plan, was signed by China and GAVI/vaccine fund representatives that spelled out the financial and operational commitments of all involved parties. An implementation plan of such detail with high-level agreement had not been a feature of previous GAVI-supported work in other countries.

The vaccine provided for the project was not through UNICEF, as GAVI had done for all other countries; instead, GAVI provided funds to China for domestic vaccine procurement. The reason for this was that China itself produced hepatitis B vaccine, and provision of UNICEF vaccine would impact the domestic market. However, China vaccine was not WHO-prequalified, and the national regulatory authority was only in the process of demonstrating that it was fully functioning. There were concerns that GAVI would be providing funding for the purchase of a vaccine that was not WHO-requalified. The GAVI project was one factor among others that helped to move forward the approval of the national regulatory authority.

Previously, vaccine procurement had been at the provincial level, but the project moved this for hepatitis B vaccine to the national level, increasing the capacity of the $\mathrm{MoH}$ and the China CDC National Immunization Program to conduct such activities for vaccine and injection equipment.

One of the criteria for receipt of GAVI support was formation of an interagency coordinating committee (ICC), which included representatives of the $\mathrm{MoH}$, China CDC, WHO, UNICEF, DFID, the World Bank, the China Foundation for Hepatitis Prevention and Control (an NGO led by former MoH official Wang Zhao which also played an important advocacy role in the project), PATH, and others. Committees addressing general immunization issues with such broad participation had not existed before in China, and the ICC facilitated progress related to the project and larger topics (including immunization financing). 
The project was a stimulus for conducting studies and demonstration programs in China to address other issues related to routine hepatitis B immunization, including improving timeliness of the birth dose and catch-up immunization.

From 2002 to 2011, the project progressed with the input of a number of generations of GAVI co-managers. First, Dr. Craig Shapiro and Dr. Xiaojun Wang were involved with project inception and initial implementation. Second, Dr. Steve Hadler saw major progress in three-dose vaccine coverage, which allowed them to focus more attention on the timely birth dose. Third, Dr. Yvan Hutin and Dr. Fuqiang Cui dealt with the final evaluation, which included a large mission throughout China for data collection in three strata of 80 clusters in October 2010.

Among many enlightening and delightful experiences while working in China, what stood out most strongly was the ability to plan and successfully execute public health programs, ranging from hepatitis B vaccination in least developed provinces and counties, to enhanced surveillance for meningitis and encephalitis, to measles and polio vaccination campaigns. During the tenure of Dr. Steve Hadler, his major responsibility was to help guide implementation of the GAVI-funded hepatitis B vaccine project, aimed at reaching high coverage with timely birth dose and full 3-dose series of hepatitis B vaccine among 12 less advantaged western provinces and poorest counties in 10 middle provinces. Ultimately, this project was remarkably successful, bringing coverage indicators in western provinces from $49 \%$ to $85 \%$ on time birth dose and from $68 \%$ to $89 \%$ HepB3 by 2009 [6].

Several factors were key to this success, most notably the co-leadership of the China $\mathrm{MoH}$ and China $\mathrm{CDC}$ nationally and at each administrative level reaching down through province, prefecture, and county. China CDC brought the scientific expertise and basic strategies, as well as monitoring, and the $\mathrm{MoH}$ and bureaus of health at provincial and lower levels brought the authority to assure work would be effectively implemented in each hospital and clinic. Hence, the basic strategies for giving timely birth dose - first assuring hospitals took responsibility for providing the birth dose "he who delivers the infant gives the vaccine dose" - were systematically implemented in every hospital, reaching $98 \%$ coverage with timely birth dose among children born in hospitals. This success was based on training conducted jointly by China National and Provincial CDC technical experts and Health Bureau leaders; intensive monitoring including vaccine registers in the delivery room and at county health clinics, using key indicators; and biennial reviews in selected areas, with feedback reasons for low coverage (unstable at birth and transferred to pediatrics, low birthweight, etc. - none of which were actual contraindications). Assurance of high coverage in each hospital is owed in large part to the authority of the leaders of health bureaus and provincial and county CDCs.

Another key factor which contributed to the success was a concurrent national policy to reduce maternal mortality, through promoting births in hospital, especially in rural areas where these had previously occurred at home. This had been established as a national initiative and rigorously implemented through subsidies to expectant mothers in rural areas to give birth in hospitals and resulted in dramatic increase in births in hospitals in all areas. This coincided with efforts to achieve high on-time birth dose coverage in every hospital and hence drove remarkable increases 
in timely birth doses in project counties [7]. At the same time, the GAVI team had worked hard to learn how to deliver birth doses for rural births while improving coverage in hospital births - promoting registration of pregnant women, tracking prenatal care, assuring vaccine could be brought to the village in time for the birth, trying to get vaccine licensed for use off the cold chain (scientifically valid), and achieving high coverage in demonstration projects in Qinghai, Gansu, and Ningxia [8]. Yet this work was ultimately superseded by the national initiative to bring deliveries into hospitals, to the greater health benefit of mother and child - and so that by project end, an estimated $84 \%$ of births were in hospitals in these least advantaged counties in China.

A third factor that contributed to the success was the ability to track progress at all levels. Although China has always excelled at compiling statistics, a persistent challenge was the unavailability of exact denominators at any level, due primarily to out-of-plan births and migration. In general, tracking of immunization coverage relied on locally determined denominators for each vaccine dose and resulted in coverage usually exceeding $95 \%$ at each level - not unusual for administrative vaccination systems in any country but relatively useless for tracking progress. For the GAVI project, we instead chose to compare HBV3 and on-time birth dose coverage to those of other EPI vaccines due at roughly the same time - DTP3 and DTP1. This provided measures and achievable targets for each dose, which could be tracked at each level. Ultimately, these indicators were also used to help guide choice of districts in which to do evaluations, allowing selection of high, middle, and low performers to compare strategies and progress. Although these indicators did overestimate total coverage (not including children who did not receive DTP1 or DTP3), they presented the best approach for this project based on timeliness and providing information at each level.

During our tenures, there was occasionally tension, particularly with the opportunities to do direct monitoring in the project provinces (usually only annually except in special WHO-funded projects). However, with the system of feedback and oversight, even the periodic field supervisions were ultimately converted into strong progress in improving the project. Although field opportunities were not always as often as hoped, these were always both eye-opening and delightful. It was a privilege to work with talented and conscientious colleagues at national, provincial, and local levels and their ability to convert plans into action even in the most remote and challenged areas. Seeing the scope of the Chinese geography, the various peoples and ethnic groups were fabulous. And of course every field visit had its nonwork attractions, from the inevitable sightseeing trips to such historical places as Yan'An, Shaanxi, where Chairman Mao and the communist party spent the several years after the Long March; districts in Sichuan where Long March fighting occurred; the high plateaus and Buddhist monasteries of Qinghai; and the beautiful mountains and rural areas of Yunnan, Ningxia, Gansu, and Guizhou. And not to mention the inevitable banquets, with the rich variety of local dishes, bai jiu contests, and sange nege tournaments.

While the success of the GAVI China in terms of hepatitis B vaccine coverage and reduction of prevalence of chronic hepatitis B virus infection was widely disseminated through scientific communications and publications, the results in terms 
of injection safety had not been documented so systematically. Hence, in 2010, as part of the final evaluation of the project, China CDC evaluated immunization injection safety using the standardized WHO assessment tool. Results of this observational assessment indicated that over 10 years, major progress had occurred. Glass syringes had disappeared, and locally produced auto-disable syringes had become the norm [9].

Aside from the direct output of the GAVI project, the achievement of uniformly high coverage for the third dose of hepatitis B vaccine, the birth dose, and the injection safety, the GAVI project was a tremendous learning opportunity on all sides. First, we all learned through trial and error what was the best way to make the program work in a country as large and complex as China. In fact, the spirit of these pilot projects for the timely birth dose was exactly about that: let's try together, plan it together, monitor it together, and troubleshoot issues that come up together until we succeed. Second, on the side of the Chinese counterparts, many China CDC staff got professional development opportunities that allowed them to further apply their skills in other challenging settings afterward, in China or internationally. Dr. Fuqiang Cui actually used the experience acquired with the final evaluation of the project to defend a $\mathrm{PhD}$ at the University of Basel. Third, while the project was wrapping up, WHO and China CDC thought that it would be important to review practices in terms of viral hepatitis surveillance. A joint mission was then organized that formulated recommendations in the field of surveillance of acute hepatitis and chronic infections. Fourth, on the side of the international colleagues, everyone worked hard on his Chinese, each with its own focus. Dr. Steve Hadler was very much into characters, numbers, and proper nouns, so he was rapidly able to read the tables and figures in Chinese, and Dr. Yvan Hutin invested in the HSK, the Hanyu Shuiping Kaoshi, the Chinese language exam, after Dr. Fuqiang Cui has ambitioned for him to try to graduate from the Chinese primary school exam before he would leave China. Last but not least, following an idea from Dr. Mark Kane and active editorial work by Dr. Steve Hadler, the entire GAVI China experience was recorded as a special issue of the Vaccine journal (Vaccine 2013;31 (Suppl 9)) so that public health officials working to increase hepatitis B vaccine and timely birth dose coverage in other countries could get inspiration from the positive experience in China.

The ultimate success of the project can be attributed to the vision of public health leaders and Chinese hepatitis experts in generating the data to stimulate the need and to the dedication of the many individuals within the $\mathrm{MoH}$, the national and local CDCs, the immunization providers, and international partners. Making hepatitis B a routine immunization likely would have happened eventually without GAVI support, but at a later time, with the massive changes brought about by the SARS epidemic and the overall economic development in China. The China-GAVI project, consistent with the overall goals of GAVI, served as a catalyst to make this happen earlier and set the stage for full implementation. The thousands of children who are protected from hepatitis B virus infection, and therefore will not develop liver cancer or cirrhosis due to the hepatitis B, are the direct beneficiaries of the work of all involved. 


\subsection{China's EPI and Measles Elimination Programme Looked Back in the JICA Project's Point of View}

Yasuo Chiba, Hiroshi Yoshikura

Japan's cooperation for poliomyelitis eradication, the China Polio Control Project, JICA, launched in 1990, and it aimed at establishing its activity model in Shandong province (Fig. 10.2). We collaborated with provincial epidemics prevention station (present CDC) to begin AFP surveillance, supplemental immunization, and poliomyelitis laboratory diagnosis. As to the laboratory, the National Institute of Infectious Diseases, Japan, has provided technical support, and it has also contributed to build national laboratory network system. Two years later, the cooperation expanded to four neighboring provinces, Hebei, Henan, Anhui, and Jiangsu, and from 1995, it shifted to southern five provinces, Sichuan including Chongqing City, Yunnan, Guizhou, Guangxi, and Jiangxi. In these provinces, we have visited more than 300 major medical institutions, where we reviewed their implementation of AFP surveillance. We also collaborated with the provinces of Xinjiang, Qinghai, and Gansu, which have been facing polio importation from polio-endemic neighboring countries. The JICA project continued in the several phases of similar activities even after China achieved polio free as a member state of WHO Western Pacific Region in 2000.

China's public vaccination service, the Expanded Programme on Immunization (EPI), began in the late 1970s, and by the middle 1990s, the most provinces had achieved high $(\geq 85 \%)$ coverage at township level with four classic vaccines, BCG,

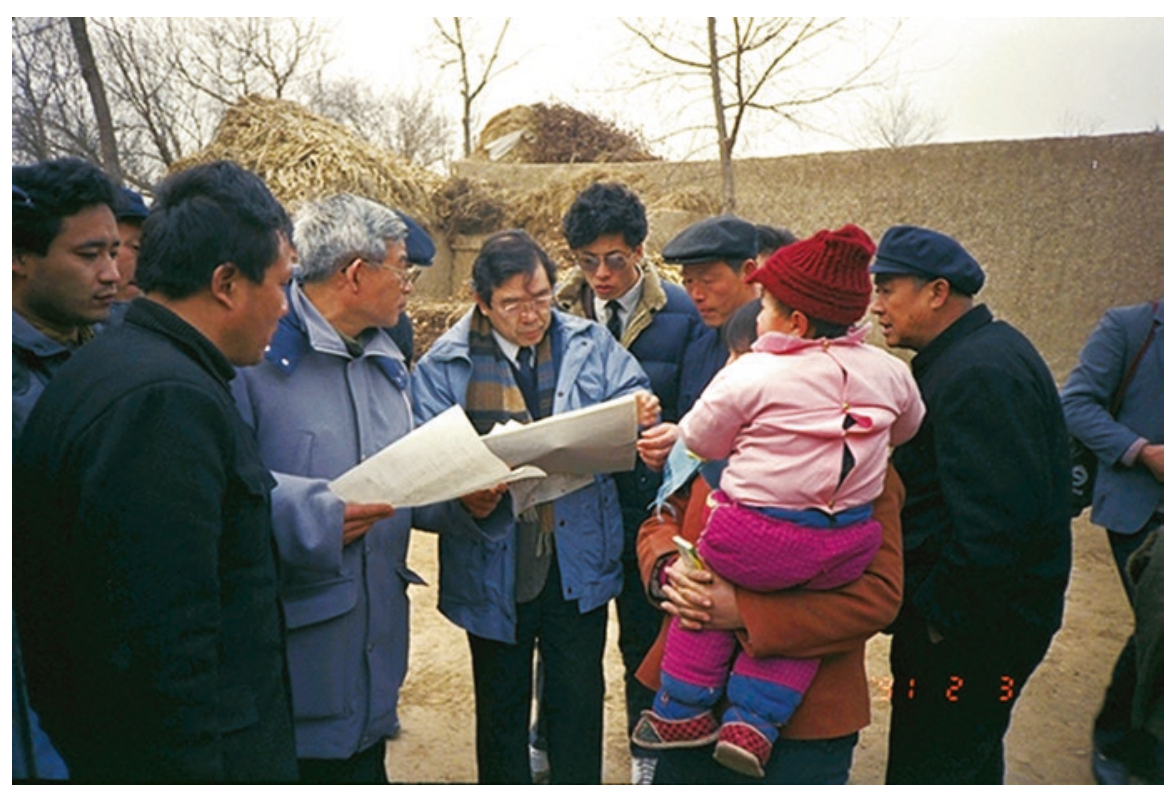

Fig. 10.2 Door-to-door survey about a polio case in a farmhouse in rural Shandong province (February 1992) 
DPT, polio, and measles. Despite this overall success, polio outbreaks have recurred from the end of the 1980s, mainly in eastern provinces including Shandong. In order to figure out the various causes behind the outbreaks, we have visited and investigated widely rural agricultural areas where cases with polio were reported. This action uncovered as-yet-unrecognized problems of EPI as well as conditions responsible for the polio outbreaks, and it has also provided information about other vaccine-preventable infections, such as measles.

During the 1990s, China was in the developmental stage of economy, and provinces which can afford EPI services satisfactorily were rather rare. Budget amounts to maintain or replace cold chain equipment were generally small at any administrative level, and, therefore, in prefecture and subprefecture units, for example, vehicles for vaccine transportation, walk-in cold rooms, and other cold storages appeared extremely old. Similarly, in rural vaccination posts, ice packs and injection syringes often run short relative to the size of target population, suggesting that the vaccinations in such posts might have resulted in unsafe and unsuccessful ones. Two other factors, rapid increase of floating families and high childbirth rate, further negatively affected EPI activities by leaving a number of children out of vaccination services. Village health workers appeared to have been insufficiently trained for accomplishing their duties and have received only a small amount for their work. Nevertheless, they had to bear all the burden derived from these problems. Indeed, the coverage of routine as well as supplemental vaccinations seemed to depend to a great extent on their motivations. Village health workers did a wide range of jobs, from registration of newborns, vaccine transportation, preparation, and sterility of injection equipment, till house-to-house visits for vaccination. These amounts of duties might have exceeded their capability particularly at a time when the supervision and support were insufficient. However, the progress of EPI in China was remarkable after the middle of the 2000s, when the government further increased commitment and financial support.

In October 2014, we visited several new vaccination posts, so-called vaccination clinic, in the townships of Shandong and Gansu. Vaccinations in a fixed site started in the early 2000s, replacing gradually the old practices which had been carried out in villages for a long period. Shandong is one of the provinces which played an important role for the promotion of such a system in China. Vaccinations in the clinics have been improved significantly than before. Once, an ampule containing multiple doses of vaccine was cooled on ice until finishing several injections, a procedure which might affect sterility and cooling of the preparation. But today the most preparations are for single use and have been kept in a small refrigerator on the desk just until injections. Vaccinations have been done by trained EPI staff. It was not until recently that parents were requested to sign a consent form after EPI staff's explanations about their child's vaccination. Administrative works also appeared to be improved since EPI registration, and the recording of vaccinations has been done on personal computers in many clinics. Further efforts, however, should be made to reach to children who are out of vaccination service, including those of migrant worker families, in order to close immunization gaps.

Having achieved remarkable vaccination services as well as polio free, measles elimination would be the next target of China's EPI. In the year 2005, WHO in the Western Pacific Region proposed an initiative to eliminate measles by 2012, and for this purpose, the JICA project also has collaborated on the activities of this country. 
In 2010, China conducted national-scale supplemental immunization activities (SIAs) of measles-containing vaccine (MCV), although many provinces have been strengthening vaccinations by their own policies. As a result, a historic low of about 6000 measles cases were reported nationwide in 2012. The outbreaks, however, resurged in 2013, and it increased to over 40,000 cases in 2014. In Shandong province, about 2000 measles cases were reported in the same year, with the age being distributed widely, involving infants before vaccination age, adolescents, and young adults. A number of patients in the older age groups had a history of vaccination by $\mathrm{MCV}$, and it was therefore assumed that the previous weakness of cold chain systems might be related to the vaccination failure in those patients.

The elimination of measles is more challenging than that of polio. In the poliomyelitis eradication, National Immunization Days campaigns with oral polio vaccine $(\mathrm{OPV})$ successfully interrupted the transmission of wild poliovirus in China. Children were administered with OPV in every corner of the country, including even the marketplace, railway station, etc., while MCV has to be administered only by injection in the well-equipped clinics. In addition, measles virus is so contagious that transmission to others would occur easily if susceptible subjects remained in the population. The chance of infection increases as the population become larger, which is really the case in China with population 1400 million, equivalent to $19 \%$ of the total world population. Thus, the interruption of measles virus transmission by SIAs may be more difficult than that of poliovirus. It would be better to focus more on subjects who have no definite evidence of vaccination with the second dose of MCV rather than to target certain age range as a sole requirement. This policy might be practical and cost-effective in reducing measles susceptible population further.

Measles elimination in Japan also took time until it was verified as "measles endemic transmission free" (though 299 cases were reported in 2013 and 482 in 2014 [as of January 2016], which were considered imported or importation-related). It was accomplished by the introduction of routine second dose of MCV and achieving its high coverage in broad age range including adolescents. Although China's measles vaccination coverage seems high, continuous efforts would be needed to promote and secure vaccinations with the second dose of MCV. As a long-term policy, strengthened collaboration with Maternal Child Health $(\mathrm{MCH})$ programs may worth consideration. In Japan, Pediatric Association and other groups related to $\mathrm{MCH}$ played an important role for the promotion of public awareness about measles elimination and the vaccinations for it. Ultimately, such a collaboration will be useful for further development of overall EPI programs as well. In any event, the measles elimination program in China, as my hope, should be the one which can raise further the quality of routine immunization services in the future.

\subsection{Experience from Andrea Gay}

\section{Andrea Gay}

Prior to China's decision in 2005 to eliminate measles, my knowledge of China's immunization system was very superficial despite 40 years of intermittent, varied experience with Chinese in the United States and in China, including 5 years 
involving primary health care, that previously shaped my understanding of China's immunization program.

Beginning in the 1970s, my experience working with the Chinese population in San Francisco, California, to provide primary health care to this community indirectly formed my expectations about health care in China. For instance, I believed that once a public health intervention (e.g., vaccination) was required by the national government in China, it was expected to be followed with full support from Chinese people. As the community health center program in San Francisco was funded by the US Federal government, the Chinese community expectation was that the health services offered would be for their protection and should be accepted and used. Most of the program administrators and community residents were immigrants from China accustomed to having a government collect data so this health center always met the US Federal government requirements for timely and complete data. The health outcomes achieved and measured by the data ensured that this health center continued to have their annual grant requests fully funded.

During this same period in China, vaccination was viewed as one important preventive health activity. Recent Chinese immigrants in San Francisco brought this acceptance for vaccination with them. In China, despite high demand, the vaccine supply was often insufficient so many people in remote rural areas simply did not have opportunities for vaccination, creating a significant cohort of older Chinese immigrants without vaccine protection against various diseases. This led to a strong vaccination program in San Francisco's Chinatown to protect both children and adults.

When I taught in China in the mid-1980s, rapid changes to every aspect of life were just beginning, and optimism for change was high despite the unimaginable scale of effort required to develop a very populous poor country with a mostly rural population. In conversations with my students (all college graduates) coming from over half of China's provinces, I learned that many of them were not vaccinated because the vaccine supply had not been sufficient to reach distant rural areas, in many of their provinces. Health workers and doctors worked hard to vaccinate all children, but without vaccines, this was an impossible task. I gathered from these discussions that China's immunization program was highly valued in a population who valued prevention and were compliant with public health goals set by government. Yet even with a well-organized program which included collection of detailed data, the constant lack of sufficient resources (vaccines, supplies, health workers, finances) to provide needed vaccinations for a rapidly growing population would jeopardize attainment of national disease elimination goals. Discussions with my students led me to believe that when a goal was established in a national 5-year plan, there was intense pressure on officials to achieve this goal. To set and achieve a national goal, collecting data to measure the achievement was an approach to problemsolving that the Chinese population understood and is still used effectively today.

It was not until 2006 that I actually was able to work with the Chinese government's Ministry of Health, the China Centers for Disease Control, and the China offices of WHO and UNICEF on China's immunization program. I was then working at the United Nations Foundation (UNF), one of five (World Health Organization, UNICEF, American Red Cross, US Centers for Disease Control, 
UNF) founding member organizations of the Measles Initiative, a global effort to eliminate measles worldwide. China's success in eliminating measles is key to the regional and global elimination of measles, and international organizations wanted to support China's efforts in whatever way possible. Measles elimination became a goal in the 2006 National 5-year plan with financial resources allocated to various levels of government to achieve elimination. However, measles is stubborn, and, 3 years past the original target date for the goal, measles still lingers in various provinces.

In 2006 at one of the WHO regional meetings, I was surprised to learn that vaccination data from China was incomplete, or at least the data shared with international agencies at that time was incomplete. I expected to find detailed data from all parts of China analyzed to determine what had been achieved and what still needed to be done to eliminate measles. I assumed the capability for data collection existed and that Chinese followed vaccination requirements for their one child before or by registration for preschool. Coordination of data between clinics and schools was established to ensure all children received vaccinations. The impact of China's many simultaneous and rapid development changes over a short time strained the health system leading to uneven progress among provinces as they developed. The one-child policy and increase in early school registration might logically be expected to increase vaccination rates, while the growing floating migrant population might decrease vaccination rates as the rural population increasingly migrated to township and urban areas without always registering their move. Ensuring accuracy of data became increasingly critical and difficult with these developments. However the measles elimination goal with a target date made accurate and timely data more critical than previously.

When, in 2008, I began to make field visits to Chinese provinces to understand the capacities and specific problems, I found that detailed data was indeed available and coordinated at various levels between health and education ministries, that recent technology being used was more advanced and wider spread than in most developing countries, and that the problems were more focused on the floating migrant population and the sparsely located minority populations in rural areas.

These supervisory visits to provinces were fascinating. In virtually every site we visited over several years, the data available was very detailed, and the analysis noted both strengths and weaknesses. The most common weakness was the surveillance system in timeliness of sample collection and lab capacity. In meetings with various health officials - at provincial, county, and prefecture levels and in hospitals, clinics, and schools - it was possible to better understand each situation but very difficult to be useful in suggesting possible solutions, particularly where both human and funding resources were insufficient to support increased technical activities.

These field visits to provinces, where data was shared and discussed openly in detail, were crucial to a clearer, more detailed understanding of the challenges and constraints facing public health officials at all levels of government in China. These visits also provided the only opportunity international colleagues have to interact directly and informally with Chinese colleagues who must implement solutions, 
often without adequate training or exposure to alternative solutions used successfully in other places.

In my previous experiences with young Chinese, I often sensed a lack of confidence in what they think they know because of limited exposure to and interaction with other countries' immunization programs. Simultaneously they have great confidence in their individual ability to achieve solutions if given the opportunity (including resources). International colleagues are most useful when encouraging Chinese colleagues to feel confident in their ability to find solutions to specific problems by regularly sharing experiences among colleagues in different provinces (both what has and has not worked). International colleagues can share experiences from other countries, especially countries with similar issues such as highly mobile populations and diverse ethnic populations. International colleagues can also be useful working with Chinese colleagues to increase various uses and forms of communication, including messages about immunization data, goals, and the value of prevention. I found Chinese colleagues to be strong technically and well ahead of most countries in using the newest technology to manage data at all levels in their immunization program. One of the most useful roles international colleagues can do is bring global attention to and appreciation for the really significant immunization achievements in China. This attention can be used to encourage the Chinese government to increase support for the immunization program as a leader in disease control for vaccine-preventable diseases.

China's historical inexperience with sharing data internationally sometimes made it difficult for international staff to offer useful ideas/approaches except in general terms. In the past 5 years, this has changed considerably, and currently the $\mathrm{MoH}$ publicizes measles data by province on monthly basis through $\mathrm{MoH}$ website. China now has a well-functioning immunization system valued highly by the Chinese population with mostly accurate and complete data available to analyze and use to improve immunizations. Work to strengthen surveillance is underway to make it more sensitive and timely to verify absence of endemic measles virus in China.

Public health community open and willing to identify and discuss key technical and programmatic issues increase political commitment and provide sufficient financial and human resources. Health officials at all levels of government know the problems and work hard to rapidly solve problems.

I would like to acknowledge the tremendous efforts undertaken by all Chinese people to protect their children from diseases by vaccinating them. The scale of China's national vaccination program is staggering and continuous with each new birth and despite occasional setbacks continues to improve and expand as new vaccines or combinations of existing vaccines become available. China has already eliminated several diseases by protecting their population with vaccination. My admiration for China's public health work continues to grow each time I experience the energy, competence, and dedication of government staff responsible for ensuring the quality and acceptance of China's immunization program. China's public health officials open sharing of data and appreciation for support from the international public health community encourages everyone involved to help achieve immunization goals set by the Chinese government as rapidly as possible. 


\subsection{Building National Regulatory System to Protect Public Health in China and Opening Pathway for Vaccine Industry to Contribute to WHO Expanded Programme on Immunization}

\section{Lahouari Belgharbi}

China is one of the main vaccine producers of vaccines with a set of 41 vaccine manufacturers (as of 2013) producing yearly more than one billion of doses of vaccines (as of 2013) and is 100\% self-sufficient for its own national immunization program. The production has increased significantly from 700 million and 38 types of vaccines to over 900 million of doses with 55 types of vaccines. The lot release data shows also that the quality of the domestic production had increased as the number of lot rejected failed from 30 in 2009 to 4 in 2013. It is expected that the next vaccines that will be prequalified will be soon an influenza vaccines that will contribute significantly to secure the global vaccine supply in case of epidemic. Moreover other vaccines are also expecting to increase the portfolio of WHO-prequalified vaccines and that can be produced in large volume to satisfy the export market.

Since 1998, the Chinese government has aimed to build up a stronger and modern national regulatory system; this was documented through the different national strategic plans that emphasized the need for the government to strive to meet the highest WHO standards of quality, safety, and efficacy for all health products and technologies. In 2001, WHO has proposed to the Government of China to develop a specific program for strengthening the national regulatory authority (NRA) represented by the Chinese Food Drug Administration (CFDA) and its affiliated institutions in the area of vaccines. Knowing the potential impact of Chinese production on the global supply of vaccines and the decrease of vaccine-producing countries from 63 in 1990 to 44 in 2013, WHO has made special efforts since 2001 to assist the Government of China to strengthen the vaccine regulatory capacity with a longterm objective to prequalify Chinese vaccines and contribute to sustain global vaccine production. Since 2001, WHO conducted regular formal and informal assessment (2001, 2003, 2005, 2007, 2009, and 2011) with development of institutional development plans (IDPs) and several road maps. This has led to an intensive capacity building efforts that successfully helped to bring the NRA to become functional in April 2011 following the assessment of December 2010 and allowed the prequalification of the first Chinese vaccines (JE vaccines) in October 2013. This has now open the pathway for the Chinese vaccine industry to become a major manufacturer of WHO prequalified for traditional EI and new vaccines knowing the important portfolio of domestic vaccines produced. It is expected that about ten new products will be submitted between 2016 and 2020 to be WHO-prequalified vaccines from China (e.g. hep.A, bOPV, seasonal influenza, typhoid Vi conjugate sIPV*, measles, oral cholera vaccine, HPV (1), HPV (2), PCV 13, LAIV).

Prior to this program, some in-country training activities were conducted mainly in the area of good manufacturing practices and quality control laboratory testing. WHO/HQ planned and organized the first NRA assessment in July 2001 for which 
a road map and institutional development plan were developed to bring the CFDA to functionality against the WHO-published indicators. CFDA was reorganized twice during the period 2001-2007 that led to several changes in the management and regulation. WHO noted that the regulatory system despite some improvement was still meeting some constraints: several regulatory functions needed much improvement such as system for the governance and transparency part, the lot release and laboratory access functions, the pharmacovigilance, and oversight of clinical trials. Only two functions had improved slightly: regulatory inspections and marketing authorization functions. Finally, late August 2007, the CFDA expressed the desire to be reassessed for meeting the WHO vaccine prequalification and requested WHO to develop a road map to meet these expectations. As a matter of fact, the convergence of Bill and Melinda Gates Foundation investment in regulatory systems and the wish of the Government of China to get prequalified vaccines from China with the availability of the WHO technical leadership in this area did build an opportunity for a long and fruitful collaboration. This also helped to obtain the needed resources from Government of China for making this happen.

The first road map developed with these new supports aimed primarily to bring the Chinese NRA to become functional by the end of 2009, and then a second road map (2010-2014) aimed to get the first prequalified product for JE vaccine; this was done in close collaboration with the JE PATH project in the Chengdu Institute of Biological Products (CDIBP). The road map planned for the WHO NRA assessment to take place in 2009 or early 2010. It included a series of learning and training activities including self-assessment and WHO and CFDA field visits targeting all domestic vaccine manufacturers. Several WHO follow-up visits were organized to monitor the road map (17 visits). A review of the pharmacovigilance and GMP enforcement was done for selected provinces and all eight major vaccines producers (mainly CNBGs institutes) and several private companies producing with potential priorities vaccines produced or to be produced such as influenza or EPI vaccines. The WHO NRA assessment was conducted in December 2010, and an official announcement of the NRA functionality was announced in early March 2011 once the compliance report was considered as fully implemented. The WHO team was composed of regulatory and immunization experts from all WHO regions (the USA, Indonesia, Mexico, Egypt, Portugal, Thailand, WHO WPRO and HQ assessors) (Team leader: Lahouari Belgharbi).

Initially the official agency in charge of medicines regulation, including biologicals, traditional medicines, diagnostics, and medical devices was established in 1998 and named the "State Drug Administration (SDA)," and then in 2005 the name was changed to "Chinese Food Drug Administration (CFDA)" and was moved under the supervision of the MoH (NHFPC). Finally it was renamed the "Chinese Food Drug Administration" (CFDA) since mid-2013. These changes were because the food area was merged again with the drug and cosmetic area, and the institution was removed from the NHFPC (MoH equivalent) supervision to become one institution led by one minister seating at the State Council (Chinese government). The CFDA is supervising 18 affiliated institutions and has a decentralized enforcement power through 32 provinces that have 196 affiliated institutions, while at 
sub-provincial level and municipality level, there are 356 administrative institutions and 560 affiliated institutions, and at county level, there are 2594 administrative institutions and 1134 affiliated institutions. The total staffing of all these institutions is 103,597 persons including 61,544 persons assigned to administrative organizations and 42,053 persons in the affiliated institutions. The scope of their work covers pharmacy, medicine, food, medical devices, public health, chemistry, law, economics, management, and related activities. The main affiliated institutions are the National Institutes for Food and Drug Control, Center for Medical Device Standardization Administration, Chinese Pharmacopoeia Commission, Center for Drug Evaluation, CFDA Center for Food and Drug Examination and Inspection, CFDA Center for Drug Reevaluation, CFDA National Center for ADR Monitoring, National Committee on the Assessment of the Protected Traditional Chinese Medicinal Products, CFDA Evaluation Center for Health Food, Center for Medical Device Evaluation, CFDA Center for Complaint and Report, CFDA Service Center, Information Center of CFDA, Chinese Food and Drug Supervision Data Center, CFDA Institute of Executive Development, CFDA Safety Emergency Drill Center, CFDA Center for the Certification of Licensed Pharmacists, China Center for Pharmaceutical International Exchange, CFDA Southern Medicine Economic Research Institute, CFDA 146 Warehouse, Chinese Medicine Information News, Chinese Medical Science, and Technology Press, Chinese Pharmaceutical Association.

The findings clearly indicated that the regulatory system has addressed several constraints and improved gradually and consistently since 2001. More progress and achievements were documented between 2009 and 2014. Moreover all WHO recommendations issued during the last WHO assessment had been implemented and thoroughly followed by one Vice Minister Mr. Zhen Wu who had been critical in the success of the first and the second assessment. WHO also continued to provide an extensive technical and substantial financial support together with BMGF since 2009, and the two road maps that were developed were achieved by meeting all expected objectives. The recent assessment also found that all regulatory functions were implemented, and performance varies between $95 \%$ and $100 \%$ of indicators met.

Some recommendations were issued to allow the Chinese system to ensure strong sustainability specially in the area of human resources where it was found that there was a need to hire urgently about 1000 staff over a period of 5 years to maintain the current workload and quality as well as to optimize the current product evaluation process by reducing timelines (more than 2-10 years for a product to be registered as more than 5000 products are submitted for registration) and also by exchanging reports (assessment and GMP inspection reports) and decentralizing or reducing redundant steps to speed up reviews. The system is already well computerized and using electronic application for all applications. Additional recommendations were made to continue the expansion of the quality management system (QMS) to all medicine areas and to all provinces to ensure consistency of regulation interpretations and decisions. Additional training is of course required, and stronger coordination was recommended to ensure a smooth decentralization decided by the state council. Serious efforts had been documented to increase the number of GMP inspections, and 
all vaccine manufacturers had been certified against the new code of GMP issued in January 2011. It is expected and planned that all medicine manufacturers should comply against the new code of GMO by the end of 2015. The pharmacovigilance had raised its detecting and reporting capacity and its reaction to address major AEFI as it was documented during the last hepatitis B events last December. There is a greater coordination and cooperation, and intensive training and communication efforts were made to cover gradually all provinces, still two provinces seem not reporting well, but the government commits to expand quickly its efforts to these provinces. WHO will help to move on this area. Additionally the oversight of clinical trials had improved, and GCP inspections were conducted as recommended by WHO with revision of the regulations to avoid conflict of interest and comply with the WHO GCP.

Finally, the assessment process was closed on 18 April 2014 with the participation of Minister Mr. Yong Zhang, the two vice ministers (Mr. Zhen Wu and Mr. Jiacai Teng), all director generals (Lin Yuan, Lifeng Wang, Guoqing Li, Wei Zhang, Jiaqi Xu, Xiaoxi Du, Xiashun Hong, Wei Yang), and all key staff members involved in the assessment, including the WHO representative and his team.

This road map was developed following the WHO NRA assessment that was conducted end of 2009; it was aimed to sustain the functionality and to ensure prequalification of the JE vaccines. The main findings indicated that the system continued to improve its performance, and it has secured its eligibility status for vaccine prequalification. Previously the Chinese regulatory system was assessed with the previous version of the indicators revised in December 2007, but another revision took place in October 2011 that endorsed revised indicators that were more stringent with additional critical indicators. This assessment was also testing a new WHO-developed software (initially tested in Mexico in March 2014) that is aimed in the near future to conduct joint assessment (harmonized) for all health product areas or technologies (medicines, blood, traditional medicines, medical devices, and diagnostics).

This road map was the consequence of the WHO NRA assessment. It leased to a joint declaration of intent that was signed between WHO and CFDA on the 3rd of July 2014. In this declaration, it was agreed during the preliminary discussion when preparing the WHO DG's visit to China that in parallel and after the signature of the declaration that WHO and CFDA will continue developing the road map and detailed action plan and an MOU or Technical Cooperation or Collaboration Agreement (both terms being used interchangeably in WHO) would be concluded as soon as feasible for the purpose of defining the respective roles and responsibilities of WHO and CFDA in implementing the road map and action plan. Then the relevant document is expected to be signed by at ADG level in WHO.

The declaration highlighted the "Mutual Intentions for Continued and Expanded Cooperation" such as to:

- Improve the regulatory system and increase appropriate capacity building activities aimed at strengthening China's regulatory capacity for food safety and medical products. 
- Promote convergence of Chinese standards with international standards and facilitate elevating the contributing role of China to the development of global norms and standards of interest to WHO.

- Increase awareness about good regulatory practices and share relevant best practices on strategic medical products.

- Foster further collaboration between CFDA and WHO on the management of food safety and the regulation of medical products.

\subsection{Experiences in China Eradicating Polio}

\section{Mac W. Otten Jr}

In the 1970s and 1980s, Brazil and the PAHO countries started the paradigm of using large (often nationwide) mass campaigns with tOPV in children $<5$ years to eliminate polio in the Americas.

In the early 1990s, WHO, CDC, Rotary, and the global polio community wanted to try to eliminate polio from another part of the world to see if the same strategies of mass campaigns and strong case-based surveillance worked outside of the Americas. WHO's Western Pacific Region (WPRO) was the region that was selected for the "trial." In 1992, three CDC former EIS officers were loaned from CDC to WHO WPRO - to Vietnam (Bernard Morniere), WPRO office (Rudi Tangermann), and China (Mac Otten) - to strengthen the effort with additional person power. Shiguru Omi (future RD of WPRO) was the WHO WPRO EPI chief at the time. I believe that I was the first CDC officer that had ever been assigned to China.

In China, my primary focal point was Bao Ping Yang, who was the MoH EPI chief. Dr. Dai was Bao Ping Yang's boss. Tao Jiang was a young computer specialist with the MoH. Li Bi Zhang was the chief polio laboratory focal point who worked with Olen Kew and Mark Pallansch at CDC. Ke-An Wang was the chief of CAPM (Chinese Academy of Preventive Medicine).

A nationwide outbreak of 10,000 polio cases occurred in China in the 2 years prior to 1991; therefore, China was very motivated to eliminate polio. The first order of business was to establish case-based surveillance with laboratory specimens. To my knowledge, this was the first nationwide case-based surveillance system in China.

Every year starting in 1992, we had an international polio program and surveillance review. Approximately 20 "foreigners" came to the review including approximately 5 persons per year from CDC. We sent them to the 20 lowest-performing counties. For some, it took 2 days to reach the county that was assigned. Many of these counties had not seen a foreigner ever or at least for many years (20-30 years). These counties were the most rural and hard to reach. This method greatly raised the political visibility of those counties which soon had high surveillance (non-polio AFP) rates.

Prior to my arrival, China's relationship to the outside public health world through WHO was very formal. However, I was an "activist" epidemiologist that would produce reams of AFP and laboratory data every week. At first, MoH was 


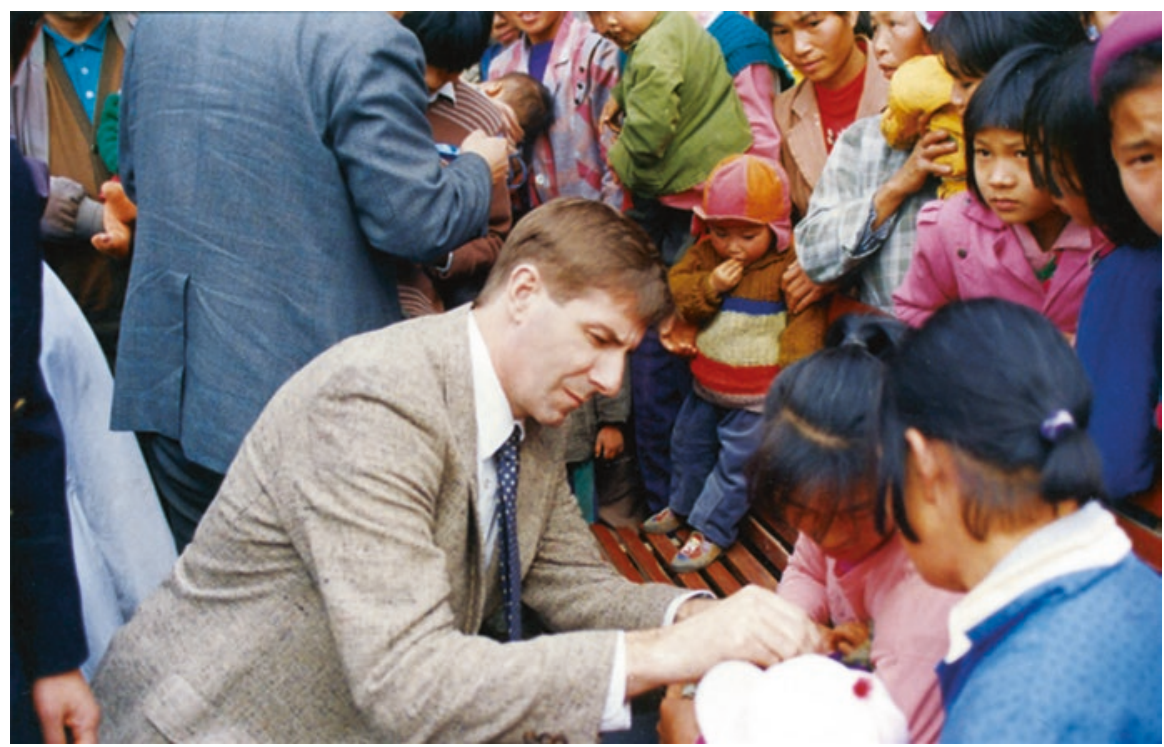

Fig. 10.3 Dr. Otten participating in a polio campaign

hesitant to share data, but trust was built over time. Bao Ping Yang was surprised to come in most mornings and find that were ten pages of analysis by county sitting on the MoH fax machine. This type of detailed technical collaboration had never happened between $\mathrm{MoH}$ and $\mathrm{WHO}$ before.

We built a computerized map of China's 2400 counties and used it extensively for public health action. It was the first county-level computerized map ever used by a health program in China to my knowledge.

A high-quality nationwide computerized AFP surveillance system was developed within 18 months, in no small part because of Tao Jiang, the MoH computer specialist. We established a decentralized provincial-level Epi-info case-based system alongside the provincial computerized EPI aggregate data system, the provincial computer files being sent to the national level every month.

The last indigenous wild poliovirus was detected within 18 months of starting the polio elimination program after just two nationwide mass campaigns. The key factors were the political will and structures to have two successful national mass campaigns, excellent case-based surveillance system, mapping of non-polio AFP rates and wild polio cases by county, and placing political attention on the lowperforming counties. The highly effective nationwide computerized case-based surveillance system with laboratory specimens showed the enormous epidemiological power of that public health paradigm.

Many, many persons at the national, provincial, and other levels can be very proud of the excellent work that they did in quickly eliminating wild poliovirus. It was a privilege to have worked on one of the earliest and largest detailed technical collaborations between China and WHO/CDC that resulted in enormous public health impact (Fig. 10.3). 


\subsection{A Short History of Measles Elimination in China: Explore Feasibility of and Prepare for Measles Elimination in China}

\section{Yoshihiro Takashima}

Since launching the Expanded Programme on Immunization in 1974, countries in the WHO's Western Pacific Region made tremendous achievements in controlling infectious diseases using vaccines and immunization programs, which include achievement of the regional polio eradication certified in 2000 and reduction of measles cases and deaths by $90 \%$ and $95 \%$, respectively, compared with the pre-vaccine era.

Despite the impressive results produced by the measles immunization programs in the Western Pacific, measles remained the leading cause of vaccine-preventable death among children in the region. There were still an estimated 170,000 cases and 32,000 deaths due to measles in the region in 2002. In addition, it was found that, with only moderate-to-high immunization coverage, there would eventually be a large measles epidemic through the build-up of susceptibles after low measles incidence or interruption of measles transmission for a certain length of time.

Right after the certification of regional polio eradication in 2000 , countries in the Western Pacific Region started more actively considering and discussing "measles elimination" as the appropriate option for combating measles so as to further reduce measles morbidity and mortality and prevent such periodic large-scale measles epidemic in the region. Then, in 2003, the WHO's Regional Committee for the Western Pacific decided that measles elimination should be one of the two new pillars with accelerated hepatitis B control to strengthen the EPI in the Western Pacific Region and confirmed that measles elimination should be a regional goal and "establishment of a target date should be made at the earliest opportunity."

How can a target date for measles elimination be established for Western Pacific Region when it encompasses the country with the largest population in the world, namely, China?

This was one of the fundamental questions that member states, WHO, and partner should answer before and even in 2003 when the region started the measles elimination initiative.

Guizhou province, with 39 million population, was one of the poorest provinces with the highest reported measles incidence of 360 per million population and $65 \%$ of all measles deaths in China in 2002. To develop a successful model for measles elimination, strengthen routine immunization program through measles elimination activities, and explore feasibility of measles elimination in a province with low level of economic development, weak immunization program, and highest measles mortality and morbidity in China, the Ministry of Health developed and conducted a large-scale demonstration project in Guizhou Province, so-called Guizhou Measles Project, from 2003 to 2009 with the support of the World Health Organization (WHO), UNICEF, US Centers for Disease Control and Prevention (CDC), and Japan International Cooperation Agency (JICA).

I joined the EPI team of WHO China Office in July 2003 and worked there until February 2009 as Medical Officer and focal point for measles elimination, 
accelerated hepatitis B control, and immunization safety surveillance. On my first day at work, I was told by the Team Leader of EPI in WHO China Office, Dr. Lisa Lee, that I should act as the WHO focal person for the "Guizhou Measles Project." I was introduced a few days later to Dr. Zuo Shuyan, Medical Officer of China CDC, responsible for measles elimination and Guizhou Measles Project. Since then, I worked with him very closely in Beijing in developing and updating the annual implementation plans of the Guizhou Measles Project and in Guizhou in testing and evaluating strategies and implementation plans for the project.

"Guizhou Measles Project" consisted of four major strategic components: (i) conducting measles supplementary immunization activities (SIA); (ii) developing and improving case-based measles surveillance with laboratory confirmation; (iii) strengthening routine immunization services; and (iv) enforcing school entry immunization requirements at kindergarten and primary school for the purpose of achieving (a) at least $95 \%$ immunization coverage in SIA at county level, (b) at least $85 \%$ coverage of the 1 st and 2 nd doses of measles vaccines at county level, (c) measles and polio surveillance meeting national performance standards, (d) sustained reduction in measles incidence to less than five cases per 100,000 populations, (e) nearzero measles deaths, and (f) zero poliomyelitis cases due to wild or circulating vaccine-derived poliovirus.

What we stressed most for the successful conduct of the Guizhou Measles Project was to ensure as high quality of implementation of these strategies as possible. For instance, all the effort was made by village health volunteers and frontline health workers and provincial, national, and international supervisors and monitors in the field before and during implementation of SIA in order to reduce the number of target children who would be missed from SIA.

All frontline health workers and village health volunteers were asked to identify and register all eligible children before SIA through door-to-door visits to all houses in all communities. Schools and teachers were asked to prepare lists of all schoolchildren eligible for SIA. Provincial, national, and international EPI experts aggressively carried out supervision and monitoring of completeness and quality of pre-intervention registration of eligible children before and during SIA. They conducted interviews to parents with eligible children in markets, checked preciseness of their knowledge on the SIA, visited communities from which people without precise knowledge on SIA had come, and checked whether or not the pre-intervention registration of eligible children and social mobilization activities had been properly carried out in these communities and any eligible child had been missed from the pre-intervention registration. They also visited as many schools as possible and reviewed completeness and quality of pre-intervention registration of eligible school-children before and during SIA. These efforts were made to improve the quality of denominator of vaccination coverage.

The practice of working with frontline health workers in the field; watching, listening, and learning from reality; and adjusting the strategies were repeatedly conducted and adopted for implementation of other strategies such as strengthening routine immunization services and enforcing school entry immunization requirements at kindergarten and primary school. 
In June 2005, the Technical Advisory Group of the Expanded Programme on Immunization and Poliomyelitis Eradication of Western Pacific Region (TAG) held its 15th meeting in Beijing, concluding that the regional measles elimination by 2012 was feasible. With this, it was recommended the WHO Regional Director for the Western Pacific to propose 2012 as the target date for regional measles elimination at the 56th session of the Regional Committee for the Western Pacific. It was then in September 2005 that the Regional Committee decided that the Western Pacific Region should aim to eliminate measles by 2012.

The China Ministry of Health took actions swiftly and organized a consultation meeting from 18 to 19 October 2005 with China CDC, National EPI Expert Committee, domestic vaccine manufactures and WHO China Office to discuss feasibility of measles elimination in China by 2012. They further invited international EPI experts on 14-18 November 2005 to prepare a draft Framework for National Plan of Measles Elimination in China, 2006-2012, and organized the second consultation meeting on 17 November 2005 to review the draft prepared by the international EPI experts. The Framework for National Plan of Measles Elimination in China, 2006-2012, was finalized and submitted to China Ministry of Health on 09 February 2016. Then, "2006-2012 National Plan of Action for Measles Elimination in China" was developed and officially issued all over the country by the Ministry of Health on 10 November 2006.

Guizhou Measles Project provided the China Ministry of Health, China CDC, and national and international EPI experts with a lot of critical lessons learned and ideas while they worked on the development of the Framework for National Plan of Measles Elimination in China, 2006-2012, and finalization of the "2006-2012 National Plan of Action for Measles Elimination in China."

Toward the end of 2012, the national and regional target year for measles elimination, China has substantially reduced measles incidence. In particular, achievements made by Guizhou Province in measles elimination were remarkable: the annual incidence rate of measles per one million population declined from over 300 before and in 2003 to under 5 in and after 2010. Experiences and lessons learned from Guizhou Measles Project were also shared with other countries in the Western Pacific Region in several annual TAG meetings.

In 2012, the Western Pacific Region marked the historically lowest incidence of measles (5.9 per 1 million population). However, in 2013-2014, the Western Pacific experienced a region-wide measles resurgence ( 17.7 and 43.8 per 1 million population in 2013 and 2014, respectively). Some countries, including China, experienced resurgence of endemic measles transmission while others, a nationwide measles outbreak following importation after a certain period of low measles transmission. Several countries, including some provinces in China, experienced increased infection and transmission of measles virus among people out of the target of current immunization strategies for measles elimination (i.e., infants aged $<8$ months, adolescents, and adults).

To make further progress toward the regional measles elimination in the Western Pacific, we should revisit the achievements made in the provinces of China that we have seen from 2003 to 2012. 


\subsection{Letter to My Successor at WHO China}

\section{Lance Rodewald}

Congratulations being selected as the WHO China EPI team lead! I am sure that you will find this job incredibly rewarding, as have all the international immunization experts in the past three decades. This job has been an incredible high point of my life - I would not trade my experience working in China for anything. During your time in WHO China, you will have the privilege of working with some of the most impressive and dedicated immunization leaders, scientists, and program professionals you will ever meet - they are the guiding force and public health army in the world's largest immunization program.

Perhaps a good way to introduce the WHO EPI team lead job is to describe the events of 1 year - so in this letter, I'll go over the most recent year - 2016, my fourth year in China. Let's get started.

The year started off with a meeting between our WHO EPI team and the MoH EPI division and China CDC NIP leadership to discuss priority activities for the year. We already knew that 2016 would be eventful because it was the year of the globally synchronized Switch of poliovirus vaccines and introduction of IPV scheduled for April. However, the work plan for 2016 included workshops on vaccine safety and regulatory strengthening, vaccine prequalification, coverage assessment, and communication strategic planning, and measles/rubella elimination. There was also renewed interest in adding new vaccines to the EPI system, which was great news because vaccines in the program are used much more effectively than nonprogram, private sector vaccines. An exciting year lay ahead.

The polio Switch loomed large. Changing 50 years of polio vaccination policy can't be easy, and for China, the challenges were monumental. Two new polio vaccines had to be developed, tested, and licensed in time to be manufactured, procured, and distributed before the Switch date - a Sabin-strain IPV 25 years in development and a bivalent OPV; the safety monitoring system had to be able to identify emerging safety signals from the new vaccines; AFP and polio environmental surveillance had to be strengthened because polio immunity would change; the coverage monitoring system had to be set to rapidly identify any drops in polio vaccine coverage; communications and educational materials for the new vaccines had to be prepared and tested; over 200,000 clinics of vaccination had to be ready to manage the new polio vaccines, and the EPI doctors had to be able to educate parents about the new polio vaccination policy; and 1 billion RMB (!!) had to be identified to pay for the new, more expensive polio vaccines.

These challenges were monumental enough, but the rigid time line made the Switch into a pressure cooker. The Switch deadline had been agreed upon by the World Health Assembly in 2012 - all 155 OPV-using countries were to make the Switch during the same 2-week period in April 2016. The Switch deadline was not a political deadline - it was a biological and epidemiological deadline, as any country continuing to use tOPV after the Switch could infect other countries by exporting type 2 vaccine poliovirus. 
In China, polio is a disease of the highest priority, and taking on risk of outbreaks was anathema. During February, our discussions with the program concerned the safety of the Switch in terms of population immunity and outbreak risk. Would one dose of IPV provide adequate protection against a type 2 virus, should one be unknowingly circulating? This was not an easy question to answer, and to make matters worse, it was becoming increasingly clear that the IPV supply situation in China mirrored the global situation - not enough IPV would be available to provide one dose per child, probably for months to more than a year, leaving some newborns with no type 2 protection.

In March, our discussions were about what might happen if China delayed the Switch for a few months to give enough time to accrue more IPV and bOPV. Asking this question sent shudders up and down all three levels of WHO, since a delay had potential to jeopardize the polio eradication effort. Globally, WHO and SAGE were holding fast to Switch deadline. Delaying the Switch would not be feasible because tOPV was no longer made anywhere in the world. China's immunization program thus faced a Hobson's choice - either switch vaccines in the face of polio vaccine shortages or break with the country's longstanding, steadfast participation in the Global Polio Eradication Initiative.

At this point in late March, it was difficult for me to think of anything worse than the possibility of a delayed polio vaccine Switch in China. But only 5 weeks before the Switch deadline, something worse did happen - the Shandong Vaccine Event. There is never a good time for a high-profile crisis, but this timing was incredibly bad. The Shandong Vaccine Event involved a criminal ring profiting from illegal sales of short-dated private sector vaccines, which were stored in a garage and eventually administered to children in hospitals and clinics. The international and national mainstream and social media were all over this story, but they had the biology wrong, as they stated with conviction and outrage that the implicated vaccines were toxic and poisoning or even killing children. Parents were frightened, confidence in vaccines and immunization plummeted, and vaccine use declined in lockstep with declining confidence.

The Shandong Vaccine Event reached the attention of top levels of government, which required forensic, remedial, and health investigations. China CDC, with other government partners, led a comprehensive and perfectly conducted health investigation of the implicated vaccines, including their stability, safety, potency, and effectiveness. Everyone in China's immunization program became involved in the health investigation, traveling to various provinces, examining records and surveillance systems looking for any health impact from the vaccines. In the meantime, parents continued to be frightened by media and social media reports. The WHO China office worked to get accurate information about vaccines and immunization to the media. Our key messages were (1) that improperly stored vaccines do not become toxic - rather, they may lose potency and become less effective and (2) that WHO is confident that vaccines that are made and used in China start out as safe, pure, and effective, based on our knowledge of vaccine regulatory oversight and safety monitoring. Additional messages included that WHO is confident in the EPI vaccine distribution system, based on evidence from effective vaccine management studies, 
and that five of the private sector, non-EPI vaccines (Hib, pneumococcal conjugate, rotavirus, IPV, and influenza vaccines) are recommended by WHO for all national programs and would be more effectively used if they were EPI vaccines rather than private sector vaccines.

$\mathrm{MoH}$, the State Council, and the program were now dealing with two simultaneous vaccine crises: the polio Switch and the Shandong vaccine event. The pressure was intense, since both were important and both were time sensitive.

China CDC's health investigation showed what had been seen in other countries' vaccine storage crises - there was no evidence that anyone was harmed by improperly stored vaccines; there was no evidence of increased VPD risk from ineffective vaccines; and there was no need to revaccinate anyone. The State Council needed to implement remedies to prevent similar occurrences, and this involved updating China's immunization legal framework - which they did in less than 1 month of the initial media reports. The rapidity with which the law was updated was possible because the immunization program had been planning for an update to the law for a few years. Indeed, there had been a publication in the Chinese Journal of Vaccines and Immunization by immunization program leadership in 2014 that outlined a vision to strengthen the program, which included improving the management of the private sector vaccines [10]. The updated law required changes in the distribution of private sector vaccines and adding additional security measures to ensure proper management of all vaccines used in China.

However, for polio, the pressure had only increased with the approaching global deadline. On the last workday before the global deadline, the State Council and the Health Commission approved stopping use of tOPV and procuring bOPV and IPV. This was the first update of the polio vaccination schedule in more than 50 years. What a month!

WHO/HQ wanted all $155 \mathrm{OPV}$-using countries to verify that they stopped using tOPV, and so China CDC and the WHO China EPI team organized a Switch monitoring site visit to two provinces, with the objectives of looking for appropriate quarantine and destruction of remaining tOPV. Monitors from UNICEF/HQ, WHO/ HQ, and WPRO participated in site visits to either Zhejiang or Guangdong provinces. Knowing the precision of China's immunization program and its ability to move in synchrony, I didn't expect that we would see a single dose of tOPV - and we didn't, except for quarantined tOPV readied for appropriate destruction. A pleasant surprise was that the clinics we visited had IPV in stock, which they obtained prior to the Switch by borrowing from the manufacturer, as official procurement hadn't started by that time.

The Switch monitoring team had the opportunity to present our findings to Dr. Jingjin Yu, the Director General of the MoH Bureau of Disease Control - the government's top technical leader over the immunization program. After we gave a glowing report about the success of the Switch in the areas we visited, Dr. Yu wasted not a nanosecond on self-congratulation. His very first question was about the global IPV supply and what WHO and GPEI are doing to minimize risk of importations and outbreaks. The message was very clear - although China stopped using tOPV, 
the global stage had not been perfectly prepared for the Switch, and this was no time to relax or let one's guard against polio down.

With the high drama of the Switch in the rearview mirror, the program was left managing an IPV shortage that would exist for more than a year - similar to the global situation. A policy move that was particularly poignant was that $\mathrm{MoH}$ moved all private sector IPV to the EPI system, which meant that more children would be able to receive their first dose of polio vaccine as IPV rather than bOPV. This policy move almost certainly spared some children from getting vaccine-associated paralytic polio (VAPP) and showed that the program will do what is needed to protect children. During the summer, I saw another example of government work to stretch the IPV supply. Kunming Institute, the manufacturer of Sabin-IPV, was asked to find a way to increase their IPV production beyond the capacity of their new facility. They decided to refurbish and reopen their facility that made Sabin-IPV for the licensure clinical trials - not an inexpensive decision, but one that will spare several million children from risk of VAPP in 2017.

Polio is one thing; hepatitis B is another. It is difficult to overstate the magnitude of China's accomplishments with reduction of chronic hepatitis B among children. Through a more than 25-year effort of escalating interventions to stop transmission of $\mathrm{HBV}$, the immunization program has enabled the current generation of children to be the first generation in China to be virtually free of hepatitis $\mathrm{B}-\mathrm{a} 97 \%$ reduction - and protected for life. This is a gift to children that keeps on giving, because stopping vertical transmission through China's laser-like focus on the timely birth dose means that when today's children grow up and have children, their children will not be at nearly the same risk. I believe that the way that HBV transmission was interrupted in China should serve as a model and inspiration to other countries. China made childbirth safer by moving delivery from homes to birthing centers and hospitals, making childbirth safer and more hygienic, and providing a platform for HBV vaccination. As a result, tetanus was eliminated, and HBV transmission was interrupted.

During the summer, the China CDC and US CDC directors decided to have the two agencies work together on health projects in Africa. Both directors have expertise in hepatitis and know that HBV is a major health problem in Africa. During the summer and rest of the year, a project to support Sierra Leone to introduce the birth dose of hepatitis B vaccine is taking shape. If this project moves forward, the China model of preventing chronic HBV will find its way to a continent where currently only 10 of 45 countries are using the birth dose of hepatitis B vaccine and where neonatal tetanus continues to take a toll.

Too much happened in fall and winter to cover in this letter, so I'll only mention two more activities - strengthening technical policy making to add new vaccines to the program and measles/rubella elimination.

EPI vaccines are expertly guided, managed, and implemented by China's program - expertly enough to not only provide individual protection but to also accomplish public health goals like control, elimination, and eradication. But private sector vaccines don't enjoy the nurturing and guidance by the program - instead, they are often more like commodities that are sold to parents, untethered to national 
public health recommendations and goals. In contrast to the uniformly high coverage of EPI vaccines, private sector vaccine coverage is low and varies by provincial and parental wealth. And in the 39-year history of EPI in China, there have been only three occasions when vaccines were moved from the private sector into the program: in 2002 for hepatitis B vaccine; in 2007 for rubella, mumps, hepatitis A, Japanese encephalitis, and meningococcal vaccines; and this year for IPV.

We had been excited to learn at the beginning of the year that there is considerable interest in $\mathrm{MoH}$ for adding vaccines to the EPI system through a strong National Immunization Technical Advisory Group (NITAG). This interest led directly to an international workshop on adding new vaccines to immunization programs that was co-hosted by the WHO China office, the Chinese Preventive Medicine Association, and China CDC. We took advantage of a meeting of the International Association of Immunization Managers meeting, which brought leaders from many countries to Beijing to discuss program management.

Immunization leadership from the United Kingdom, Germany, Malaysia, the United States, and China presented their countries' systems for making evidencebased, NITAG-supported decisions to include new vaccines into their programs. Workshop participants included MoH leadership and China NITAG members (Fig. 10.4). The most important thing that we learned is that China CDC is developing a proposal for a strengthened mechanism to add new vaccines to the EPI system. This has tremendous potential to enable China's program to have more vaccines to protect Chinese children from even more vaccine-preventable diseases - another gift from the program that can keep on giving. As a side note, we had the exciting

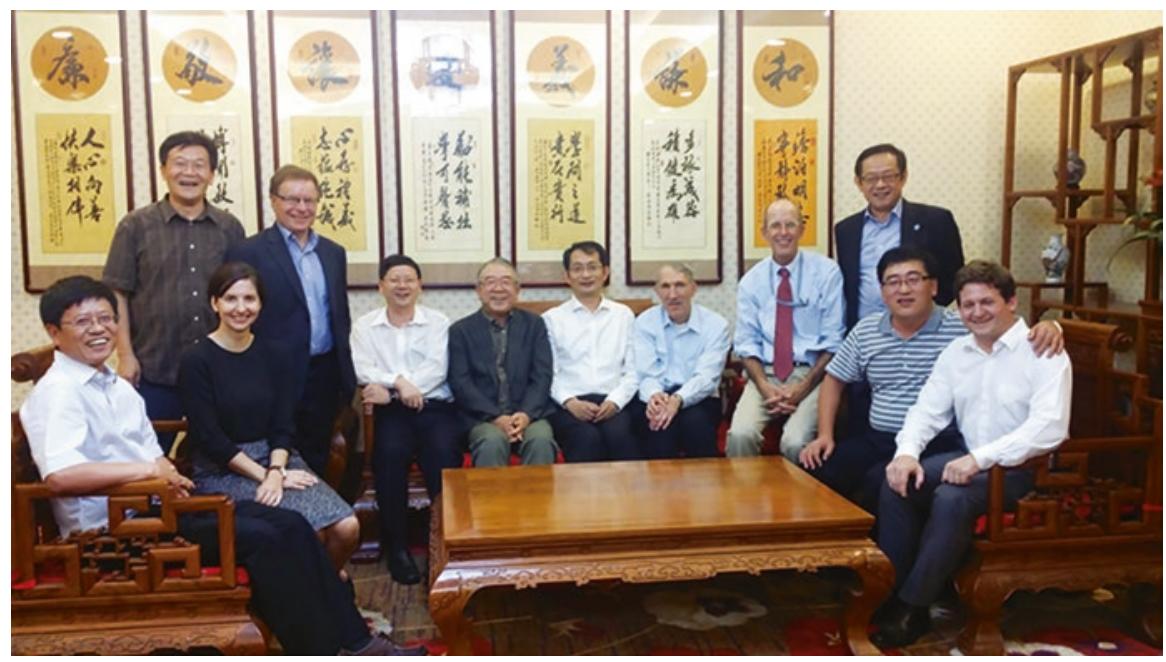

Fig. 10.4 Participants in the 2016 international workshop on adding new vaccines with a strong technical advisory group. From left to right are Drs. Huaqing Wang, Xu Zhu, Laura Davison, Anthony Harnden, Weizhong Yang, Chiba Yasuo, Jingjin Yu, Alan Schnur, Lance Rodewald, Zijian Feng, Aiqiang $\mathrm{Xu}$, and Ole Wichmann 
opportunity to visit Canada and Atlanta with China's top EPI leadership in a study tour of the Canadian and US systems for adding vaccines to their programs.

And finally, the year ended with a national and international consultation on measles and rubella elimination in China. For over 10 years, China has had a goal to eliminate measles, and during this time, a huge amount of progress was made, including conducting the world's largest SIA in 2010 when over 100 million children were vaccinated in a 2 -week period. China's measles/rubella laboratory network is world class, as is China's measles and rubella surveillance. Coverage with measles and rubella vaccines is very high, and the program has used a two-dose measles vaccination policy for 30 years. Measles incidence is down by over $99.5 \%$ compared with the pre-vaccine era. Rubella vaccine has been universally used for less than 10 year, but the incidence of rubella is already quite low in China.

Despite strong program and progress, elimination of measles remains elusive, and there is a feeling of frustration in the program that the elimination effort has not yet succeeded. The questions for the consultation were whether China is on a track that will eliminate measles; if so, when; if not, what additional efforts will be necessary to hasten measles elimination. We brought international experts on measles and rubella elimination and mathematical modelers to help address these questions. It was clear to the international experts that the challenges in China, with such a large and concentrated population, are considerable. The measles and rubella work for 2017 is becoming clear - reinvigorate the measles elimination effort with nationaland province-level plans that use all available data to identify and fill gaps in immunity; synergistically integrate rubella into measles elimination work; learn as much as possible from every measles or rubella outbreak; and use research and evaluation to identify program innovations to finish the job of eliminating measles and rubella. The measles/rubella elimination effort is going to take time, and this is going to be a significant part of your work as you assume the job of WHO EPI team lead.

As you can see, I am enthusiastic about China's immunization program. My feeling that China's program is one of the very best in the world - it is simply a national treasure. But in this letter, I've talked about the program as if it is an abstract entity. Of course, that is not the case at all. The program is composed of individuals who you will get to know during your time in the WHO office - and they are the best part of the job. You will get to work with dedicated, smart, and caring scientists, leaders, and professionals who will inspire you, just as they have inspired me and other international experts for more than 30 years. Enjoy!

\section{References}

1. Yang ZW, Zhang J, Zhang XL, Yang GH, Wang KA. An analysis of current measles epidemiological situation in China. Chin J Vaccines Immun. 1998;4(2):14-8.

2. Wenyuan Z. Expanded program on immunization. Shanghai: Shanghai Publishing House of Scientific and Technological Literature; 2001.

3. Ministry of Health. Plan for acceleration of measles control in China. Beijing: Ministry of Health; 1997. (rfMoH document no. 16) 
4. Centers for Disease Control and Prevention. Measles IgG and IgM enzyme immunoassays. Isolation and identification of measles virus. Atlanta: CDC; 1997.

5. Aiqiang X, Zijian F, Wenbo X, Lixia W, Wanshen G, Qing X, Haijun S, Lee LA, Xiaofeng L. Active case-based surveillance for measles in China. J Infect Dis. 2003;187(Suppl 1):S258-63.

6. Hadler SC, Cui FQ, Averhoff F, et al. The impact of hepatitis B vaccine in China and in the China GAVI Project. Vaccine. 2013;31(Suppl 9):J66-72.

7. Cui FQ, Luo HM, Wang FZ, et al. Evaluation of policies and practices to prevent mother to child transmission of hepatitis B virus in China: results from China GAVI project final evaluation. Vaccine. 2013;31(Suppl 9):J36-42.

8. Hutin Y, Hennessey K, Cairns L, et al. Improving hepatitis B vaccine timely birth dose coverage: lessons from five demonstration projects in China, 2005-2009. Vaccine. 2013;31(Suppl 9):J49-55.

9. Wu Z, Cui F, Chen Y, et al. Evaluation of immunization injection safety in China, 2010: achievements, future sustainability. Vaccine. 2013;31(Suppl 9):J43-8. https://doi.org/10.1016/j. vaccine.2012.11.057.

10. Lei ZL, Li QL, Li L. Review of significant achievements in EPI with awareness of the challenges to implement EPI confidently in the future. Chin J Vaccines Immun. 2014;20(5):385-9. 